\title{
Purification of the Acidic Vanadium-Bearing Solution with a Novel Approach of Chemical Precipitation
}

\author{
Juhua Zhang ${ }^{1,2,3} \mathbb{D}$, Wei Zhang ${ }^{1,2,3, *(\mathbb{D})}$ and Chengzhi Li ${ }^{1,2,3} \mathbb{D}$ \\ 1 Key Laboratory for Ferrous Metallurgy and Resource Utilization of Ministry of Education, Wuhan University \\ of Science and Technology, Wuhan 430081, China; zhangjuhua@wust.edu.cn (J.Z.); \\ chengzhi.li@wust.edu.cn (C.L.) \\ 2 The State Key Laboratory of Refractories and Metallurgy, Wuhan University of Science and Technology, \\ Wuhan 430081, China \\ 3 Hubei Provincial Key Laboratory for New Processes of Ironmaking and Steelmaking, Wuhan University of \\ Science and Technology, Wuhan 430081, China \\ * Correspondence: Wei_zhang@wust.edu.cn
}

check for updates

Citation: Zhang, J.; Zhang, W.; Li, C. Purification of the Acidic Vanadium-Bearing Solution with a Novel Approach of Chemical Precipitation. Metals 2021, 11, 625. https://doi.org/10.3390/met11040625

Academic Editor: Petros E. Tsakiridis

Received: 4 March 2021

Accepted: 6 April 2021

Published: 13 April 2021

Publisher's Note: MDPI stays neutral with regard to jurisdictional claims in published maps and institutional affiliations.

Copyright: (c) 2021 by the authors. Licensee MDPI, Basel, Switzerland. This article is an open access article distributed under the terms and conditions of the Creative Commons Attribution (CC BY) license (https:/ / creativecommons.org/licenses/by/ $4.0 /)$.

\begin{abstract}
Calcified roasting followed by dilute sulfuric acid leaching is a promising process for cleaner vanadium extraction from converter vanadium slag. However, some impurities, like $\mathrm{Ca}, \mathrm{Mg}$, $\mathrm{Mn}, \mathrm{Si}$ and $\mathrm{Al}$, also transfer into the leaching solution, accompanying V during the dilute sulfuric acid leaching, leading to the product of vanadium pentoxide prepared from this acidic vanadiumbearing solution, inferior to the product from the traditional process of sodium roasting and water leaching. A chemical precipitation method was firstly proposed to purify this acidic vanadiumbearing solution with a new prepared remover of $\mathrm{MnNH}_{4} \mathrm{~F}_{3}$, which combines neutralization and fluoride precipitation into one operational step to remove impurities of $\mathrm{Ca}^{2+}, \mathrm{Mg}^{2+}, \mathrm{Al}^{3+}$ and $\mathrm{Si}^{4+}$ in an acidic $\mathrm{pH}$ range, simultaneously. Effecting factors involved in the purification process were investigated. It was found that removals of $\mathrm{Ca}, \mathrm{Mg}$ and $\mathrm{Al}$ were all over $95 \%$ and around $55 \%$ of $\mathrm{Si}$ was removed as well at stirring speed of $200 \mathrm{rpm}$, adding coefficient of 1.6 , temperature of $50{ }^{\circ} \mathrm{C}$, reaction time of $30 \mathrm{~min}$ and $\mathrm{pH}$ of $4.50 \pm 0.05$, while the loss of vanadium was kept lower than $5 \%$, which was attributed to the reason that the purification reactions mainly proceeded on the surface of the remover. Adding flocculant of polyacrylamide was conductive to accelerating sedimentation of the precipitate and reducing the loss of vanadium. Meanwhile, the filter aid of diatomaceous could improve the filtration performance of the slurry. Ammonium persulfate could effectively oxidize and separate $\mathrm{Mn}^{2+}$ in the form of $\mathrm{MnO}_{2}$ from the vanadium-bearing solution which had been treated by $\mathrm{MnNH}_{4} \mathrm{~F}_{3}$, but performed less selectivity over $\mathrm{Mn}^{2+}$, and the loss of vanadium was unacceptable. The product of vanadium pentoxide prepared from the purified vanadium-containing solution satisfied the requirements for the standard of grade 98.
\end{abstract}

Keywords: acidic vanadium-bearing solution; purification; chemical precipitation; converter vanadium slag; calcified roasting; dilute sulfuric acid leaching

\section{Introduction}

Vanadium is widely applied in production of carbon steel, stainless steel, vanadium iron, catalysts and vanadium battery materials due to its high melting-point, high hardness and favorable corrosion resistance at low temperature [1,2]. The main vanadium industrial products are vanadium pentoxide and other down-stream products like vanadium iron, vanadium nitride and vanadium trioxide prepared with vanadium pentoxide. Presently, vanadium pentoxide is primarily extracted from vanadium slag, which is from vanadium titano-magnetite smelted by Blast Furnace and Converter Process $[3,4]$. The traditional technology for vanadium pentoxide production is sodium salt roasting-water leachingprecipitation purification-vanadium precipitation with ammonium salt [5-7]; however, this process is facing challenges of serious environmental pollution, severe requirements for 
contents of $\mathrm{Ca}$ and $\mathrm{Mg}$ in the raw materials, sintering of furnace burden and low resource utilization [8-10]. How to cleanly and efficiently produce vanadium pentoxide from the vanadium slag has become a research hot spot. Consequently, many novel vanadium extraction processes have been proposed, like low-temperature sodium roasting- $\mathrm{Na}_{2} \mathrm{~S}_{2} \mathrm{O}_{8}$ leaching [11], roasting without salt addition, sub-molten salt extraction [12-15], alkali decomposition enhanced by electrochemistry [16], direct acid leaching [17-20], magnesiation roasting-acid leaching [21], composite roasting with $\mathrm{CaO}$ and $\mathrm{MgO}$-leaching [22], $\mathrm{MnO}_{2}$ roasting-acid leaching [23], sulfating roasting [24] and calcified roasting-dilute sulfuric acid leaching [25]. Since lower-cost lime or limestone is used as a roasting additive during the calcified roasting process, no polluting gas is released, and no sodium is contained in the tailings and mother solution, which is favorable for comprehensive utilization of the tailings and recycling of the mother solution. The calcified roasting is a potentially promising process for vanadium pentoxide production in term of cost, environmental protection and feasibility of industrialization.

In the calcium roasting process, the vanadium spinel contained in the vanadium slag is oxidized and reacted with calcium additive $\left(\mathrm{CaO}\right.$ or $\left.\mathrm{CaCO}_{3}\right)$ at a temperature of $800-850{ }^{\circ} \mathrm{C}$ to form calcium vanadate. Then, the roasted slag is leached with dilute sulfuric acid at an optimum $\mathrm{pH}$ range of 2.00-3.00, and vanadium is recovered into the acidic solution. However, other elements, like calcium, magnesium, manganese, aluminum, silicon and so on, also transfer into the solution. The calcified roasting-dilute sulfuric acid leaching process was first put forward and carried out by the Tula Vanadium Factory in 1974. Hereafter, Pangang Research Institute of China also performed a lot of work on this process. However, because the problem of purifying the acidic vanadium solution was still unsolved, the purity of vanadium pentoxide produced with this process was only $93-94 \%$, and it was inferior to the product from the sodium roasting process. Hence, it is essential to find an efficient, green and economical way to remove impurities from the acidic vanadium-bearing solution.

Up to now, in most of the literature, solvent extraction [26-29] and ion exchange were used to purify the acidic vanadium-containing solution. However, when concentrations of $\mathrm{Al}$ and $\mathrm{Si}$ in the solution are higher, it is more likely that three phases and turbidity appear in the solvent extraction system. In addition, solvent extraction involves many operational steps, like reduction $\left(\mathrm{Fe}^{3+} \rightarrow \mathrm{Fe}^{2+}, \mathrm{VO}_{2}{ }^{+} \rightarrow \mathrm{VO}^{2+}\right)$, sulfonation, adjusting aqueous $\mathrm{pH}$ value, multistage extraction and multistage stripping, and these lead to large consumption of acid and alkali, and high cost. Furthermore, the raffinate and mother solution containing a small amount of extraction solvent potentially become new pollution sources since the organic solvents are usually volatile, flammable and toxic. Ion exchange is limited by relatively small adsorption capacity and is hard to apply at a large scale [30]. In comparison with solvent extraction, the operation procedure of chemical precipitation is simple, only including precipitation and filtration, and this method does not require relatively expensive organic solvents. Compared with ion exchange, the chemical precipitation is readily adapted to production capacity. Besides, the chemical precipitation used to purify the acidic vanadium-bearing solution from the cleaner calcified roasting process is the same as the purification method applied in the traditional sodium process in equipment and operation procedures, so additional equipment investment and major changes in the production line are not required if it is industrialized. Hence, using chemical precipitation to purify the acidic vanadium-bearing solution has superiority in operation, cost and industrialized application.

In the traditional sodium roasting-water leaching process, most impurities of $\mathrm{Fe}$, $\mathrm{Ca}, \mathrm{Mg}$ and $\mathrm{Mn}$ transfer into tailings, while in the calcified roasting followed by dilute sulfuric acid leaching process, impurities like $\mathrm{Ca}, \mathrm{Mg}, \mathrm{Al}, \mathrm{Si}$ and $\mathrm{Mn}$ transfer into solution accompanying $\mathrm{V}$, bringing about side effects on the vanadium precipitation procedure and the quality of the final product. To remove these impurities from the acidic vanadiumbearing solution with chemical precipitation, two requirements need to be satisfied. The first is to avoid introducing ions, like $\mathrm{Na}^{+}$or $\mathrm{K}^{+}$, which are detrimental to closed recycling 
of the mother water and will lower the purity of the vanadium pentoxide. The second is that the whole purification process should be implemented at a $\mathrm{pH}$ value lower than 5.0 , avoiding generation of vanadate precipitation caused by reactions between impurities (Ca, Mn, Mg, Fe ions) and vanadate ions, and decreasing the hydrolysate of $\mathrm{Al}^{3+}$ and $\mathrm{Si}^{4+}$, which is likely to absorb the vanadium during sedimentation. So far, little information on the purification of the acidic vanadium-bearing solution with chemical precipitation method has been reported. In our previous study, we found that when the dilute sulfuric acid leaching process was conducted at a $\mathrm{pH}$ of 2.50 , the majority impurities were $\mathrm{Mn}$, $\mathrm{Ca}, \mathrm{Mg}$, Si and $\mathrm{Al}$ (>200 mg/L), while others ( $\mathrm{Fe}, \mathrm{Cr}$, Ti) were lower than $60 \mathrm{mg} / \mathrm{L}$ [31]. In order to further figure out the effect of these impurities on the quality of vanadium pentoxide, we used the hydrolysis method at an initial $\mathrm{pH}$ of 1.8 and $96{ }^{\circ} \mathrm{C}$, and the ammonium salt method at $\mathrm{pH} 2.0$ and $96^{\circ} \mathrm{C}$ to precipitate vanadium from the unpurified vanadium-bearing solution respectively, and after calcination at $550{ }^{\circ} \mathrm{C}$ for $2 \mathrm{~h}$, the final product of vanadium pentoxide powder was obtained. The chemical composition analysis showed that the content of $\mathrm{V}_{2} \mathrm{O}_{5}$ in the product of the hydrolysis method was $94.5 \%$, and the main impurities were $2.25 \% \mathrm{CaO}, 1.72 \% \mathrm{MnO}, 0.372 \% \mathrm{Al}_{2} \mathrm{O}_{3}, 0.474 \% \mathrm{MgO}$ and $0.450 \%$ $\mathrm{SiO}_{2}$, while the product of the ammonium salt method contained $96.3 \% \mathrm{~V}_{2} \mathrm{O}_{5}, 0.401 \%$ $\mathrm{CaO}, 0.669 \% \mathrm{MnO}, 1.85 \% \mathrm{SiO}_{2}, 0.232 \% \mathrm{Al}_{2} \mathrm{O}_{3}$ and $0.341 \% \mathrm{MgO}$ [32]. These products both did not meet the standard for vanadium pentoxide of Chinese YB/T 5304-2017 [33]. The ammonium salt method could alleviate the side effect of impurities of $\mathrm{Mn}$ and $\mathrm{Ca}$, producing a higher grade of vanadium pentoxide than the hydrolysis method. As stated above, the main impurities affecting the quality of vanadium pentoxide were $\mathrm{Ca}, \mathrm{Mg}$, $\mathrm{Mn}, \mathrm{Al}$ and $\mathrm{Si}$, hence in order to obtain the qualified product of vanadium pentoxide, it is essential to remove those impurities from the acidic vanadium-bearing solution.

In this paper, a chemical precipitation method was firstly proposed to purify the acidic vanadium-bearing solution, especially to remove the impurities of $\mathrm{Ca}^{2+}, \mathrm{Mg}^{2+}, \mathrm{Al}^{3+}, \mathrm{Si}^{4+}$ and $\mathrm{Mn}^{2+}$ in the $\mathrm{pH}$ range lower than 5.00, and the influencing factors involved in the purification process were investigated. The purity and chemical composition of vanadium pentoxide prepared from the purified solution were determined to evaluate the feasibility and validity of the proposed purification method. It is of significance in providing a new insight on purifying the acidic vanadium-bearing solution and a new motivation for the industrialization of the calcified roasting process of vanadium extraction.

\section{Purification Scheme Design}

The main composition of the vanadium-bearing solution with a $\mathrm{pH}$ value of 2.58 , which was from vanadium converter slag treated by the process of calcified roasting and dilute sulfuric acid leaching, was measured by ICP-OES (Inductively Coupled Plasma Optical Emission Spectrometer, Optima 4300DV, PerkinElmer Company, Waltham, Massachusetts, USA) and the results are shown in Table 1.

Table 1. Main composition of the acidic vanadium-bearing solution.

\begin{tabular}{ccccccccccc}
\hline Element & $\mathbf{V}$ & $\mathbf{M n}$ & $\mathbf{C a}$ & $\mathbf{M g}$ & $\mathbf{A l}$ & $\mathbf{F e}$ & $\mathbf{S i}$ & $\mathbf{P}$ & $\mathbf{T i}$ & $\mathbf{C r}$ \\
\hline Concentration, $\mathrm{g} \cdot \mathrm{L}^{-1}$ & 21.4 & 5.99 & 1.02 & 1.59 & 0.200 & 0.0100 & 1.49 & 0.120 & 0.00570 & 0.0100 \\
\hline
\end{tabular}

As shown in Table 1, concentrations of impurities of $\mathrm{Ca}, \mathrm{Mg}, \mathrm{Mn}$ and $\mathrm{Si}$ are all over $1 \mathrm{~g} \cdot \mathrm{L}^{-1}$ and concentration ratios of $C(\mathrm{Ca}) / C(\mathrm{~V}), C(\mathrm{Mg}) / C(\mathrm{~V}), C(\mathrm{Mn}) / C(\mathrm{~V})$ and $C(\mathrm{Si}) / C(\mathrm{~V})$ reach up to $0.0477,0.0743,0.280$ and 0.0696 , respectively. Other impurities like $\mathrm{Fe}, \mathrm{Cr}$ and Ti are lower than $10 \mathrm{mg} \cdot \mathrm{L}^{-1}$. The solubility of $\mathrm{CaSO}_{4}$ at $25^{\circ} \mathrm{C}$ is around $2 \mathrm{~g} \cdot \mathrm{L}^{-1}$, and then the corresponding total concentration of $\mathrm{SO}_{4}{ }^{2-}$ including free $\mathrm{SO}_{4}{ }^{2}$ and dissolved $\mathrm{CaSO}_{4}$ is calculated as $1.41 \mathrm{~g} \cdot \mathrm{L}^{-1}$. After oxidation roasting, vanadium in this solution mainly existed as $\mathrm{V}(\mathrm{V})$. Since the dilute sulfuric acid leaching process was conducted at a constant $\mathrm{pH}$ value of 2.58, concentrations of $\mathrm{Si}$ and $\mathrm{Al}$ in this obtained vanadium-bearing solution were relatively high. To produce qualified vanadium pentoxide, these impurities of $\mathrm{Ca}, \mathrm{Mg}, \mathrm{Mn}$, $\mathrm{Al}$ and $\mathrm{Si}$ all need to be removed. 


\subsection{Occurrence of Vanadium in the Vanadium-Bearing Solution}

The speciation of vanadium in aqueous solution directly affects its behavior during the purification process. At lower concentrations $\left(<10^{-4} \mathrm{M}\right)$, vanadium is present as a mononuclear species within the whole $\mathrm{pH}$ range ( $\mathrm{pH} 1 \sim 14)$. At higher concentrations, vanadium exists in the form of iso-polyanions with high degrees of polymerization, and the polymeric number relates to the $\mathrm{pH}$ value. $\mathrm{VO}_{4}{ }^{3-}$ and $\mathrm{HVO}_{4}{ }^{2-}$ are stable in alkaline solution, $\mathrm{V}_{2} \mathrm{O}_{7}{ }^{4-}$ and $\mathrm{HV}_{2} \mathrm{O}_{7}{ }^{3-}$ are stable in weakly alkaline solution and metavanadate of tetramers $\left(\mathrm{V}_{4} \mathrm{O}_{12}{ }^{4-}\right)$ is the dominant species in neutral solution. Various polynuclear anionic species exist in acidic or weakly acidic solution. When the solution $\mathrm{pH}$ value is lower than 1, the structure of polymeric species is destroyed and converted to $\mathrm{VO}_{2}{ }^{+}$. The Pourbaix diagram ( $E-\mathrm{pH}$ diagram) for a vanadium-water system displays that the vanadate cation $\mathrm{V}(\mathrm{V})$ is stable and predominant in a high acidity range of $\mathrm{pH}<2$ under high electrode potential. As the potential decreases, vanadium is present as $\mathrm{VO}^{2+}, \mathrm{V}^{3+}, \mathrm{V}(\mathrm{OH})^{2+}$ and $\mathrm{V}^{2+}$ cations [30]. In the vanadium-bearing solution with a $\mathrm{pH}$ of 2.58, as shown in Table 1, vanadium exists as $\mathrm{V}(\mathrm{V})$ and its concentration is $0.42 \mathrm{~mol} \cdot \mathrm{L}^{-1}$, so vanadium predominantly exists as $\mathrm{H}_{2} \mathrm{~V}_{10} \mathrm{O}_{28}{ }^{4-}$. If the vanadium solution is pure, $\mathrm{V}(\mathrm{V})$ will appear as anions at $\mathrm{pH}$ ranging from 2 to 14 . When the impurities of $\mathrm{Ca}, \mathrm{Mg}, \mathrm{Al}, \mathrm{Fe}$ and $\mathrm{Si}$ coexist, vanadate precipitations generate from reactions between $\mathrm{V}(\mathrm{V})$ anions and $\mathrm{Ca}^{2+}, \mathrm{Mg}^{2+}, \mathrm{Mn}^{2+}$ and $\mathrm{Fe}^{3+}$ at $\mathrm{pH}$ higher than 5.0, and meanwhile, $\mathrm{Si}^{4+}$ and $\mathrm{Al}^{3+}$ begin to hydrolyze and produce strongly adsorbable flocculation with increase in $\mathrm{pH}$, resulting in a higher vanadium loss.

\subsection{Species of Impurities in the Vanadium-Bearing Solution}

$\mathrm{Si}(\mathrm{IV})$ is present as ortho-silicic acid and meta-silicic acid in the vanadium-bearing solution, which are stable in weakly acidic solution, but increasing acidity leads to precipitation of $\mathrm{SiO}_{2}$. Silicic acid is a weak acid, existing as different species over different $\mathrm{pH}$ ranges, and its isoelectric point appears at $\mathrm{pH}$ of 2 . When the $\mathrm{pH}$ value is smaller than $2, \mathrm{H}_{4} \mathrm{SiO}_{4}$ translates into cation due to protonation, like $\mathrm{H}_{5} \mathrm{SiO}_{4}{ }^{+}$and $\mathrm{H}_{6} \mathrm{SiO}_{4}{ }^{2+}$. On the contrary, when $\mathrm{pH}$ value is higher than 2, silicic acid predominantly exists as $\mathrm{H}_{4} \mathrm{SiO}_{4}$ and $\mathrm{H}_{3} \mathrm{SiO}_{4}{ }^{-}$anions. Ortho-silicic acid $\left(\mathrm{H}_{4} \mathrm{SiO}_{4}\right)$ is stable at $\mathrm{pH} 2 \sim 3$. However, if the supersaturated $\mathrm{H}_{4} \mathrm{SiO}_{4}$ solution is left for a long time, white amorphous silica precipitate will appear in the form of colloidal particles or gels, which has strong adsorbability. As the $\mathrm{pH}$ increases, the hydroxyl ions accelerate polymerization of the silicic acid, and the worst stability for the $\mathrm{H}_{4} \mathrm{SiO}_{4}$ solution occurs at $\mathrm{pH}$ around 5, where the condensation process takes the least time. In addition, within a certain $\mathrm{pH}$ range, the coagulation time for the silicic acid is inversely proportional to the concentration of $\mathrm{SiO}_{2}$ in the solution. The high concentration of $\mathrm{SiO}_{2}$ can decrease the stability of the solution and then is favorable to the polymerization of the silicic acid. Therefore, the purpose of removing Si can be achieved by increasing the $\mathrm{pH}$ of the solution to accelerate aggregation and sedimentation of the silicic acid in the solution.

In the acidic vanadium-bearing solution with a $\mathrm{pH}$ value of 2.58 , impurities of $\mathrm{Ca}$, $\mathrm{Mg}, \mathrm{Al}$ and $\mathrm{Mn}$ are present as cations, and the solubility product constants (Ksp) for their common undissolved salts are shown in Table 2 [34].

Table 2. Solubility product constants for common undissolved calcium, magnesium, manganese and aluminum compounds at $25^{\circ} \mathrm{C}$.

\begin{tabular}{ccccc}
\hline Anions & $\mathbf{C a}^{2+}$ & $\mathbf{M g}^{2+}$ & $\mathbf{M n}^{2+}$ & $\mathbf{A l}^{3+}$ \\
\hline $\mathrm{OH}^{-}$ & $5.50 \times 10^{-6}$ & $1.80 \times 10^{-11}$ & $1.90 \times 10^{-13}$ & $1.30 \times 10^{-33}$ \\
$\mathrm{CO}_{3}{ }^{2-}$ & $3.36 \times 10^{-9}$ & $6.82 \times 10^{-6}$ & $2.24 \times 10^{-11}$ & - \\
$\mathrm{F}^{-}$ & $5.30 \times 10^{-9}$ & $5.16 \times 10^{-11}$ & - & - \\
$\mathrm{S}^{2-}$ & - & - & $2.50 \times 10^{-13}$ & $2.00 \times 10^{-7}$ \\
$\mathrm{C}_{2} \mathrm{O}_{4}{ }^{2-}$ & $4.00 \times 10^{-9}$ & $4.83 \times 10^{-6}$ & $1.70 \times 10^{-7}$ & - \\
\hline
\end{tabular}

Based on the data shown in Table 2, the neutralization precipitation method is only suitable for removing $\mathrm{Al}^{3+}$ from this kind of acidic vanadium-bearing solution, and is 
not applicable to remove $\mathrm{Ca}^{2+}, \mathrm{Mg}^{2+}$ and $\mathrm{Mn}^{2+}$. For example, when the concentrations of $\mathrm{Al}^{3+}$ are 1 and $0.001 \mathrm{~mol} \cdot \mathrm{L}^{-1}$, it begins to precipitate, caused by hydrolysis at $\mathrm{pH}$ of 3.04 and 4.04 respectively, while with regards to $\mathrm{Ca}^{2+}, \mathrm{Mg}^{2+}$ and $\mathrm{Mn}^{2+}$, when their concentrations change from 1 to $0.001 \mathrm{~mol} \cdot \mathrm{L}^{-1}$, they start to deposit over $\mathrm{pH}$ of $11.36-12.87$, 8.63-10.13 and 7.64-9.14 respectively, which are in alkaline areas. Carbonate is a common impurity remover used in the chemical precipitation process, but it performs effectively to precipitate $\mathrm{Ca}^{2+}, \mathrm{Mg}^{2+}$ and $\mathrm{Mn}^{2+}$ only at $\mathrm{pH}$ higher than 8.50 [35]. It is obvious that carbonate precipitant is not suitable for purifying this acidic vanadium-containing solution as well. If $\mathrm{S}^{2-}$ and $\mathrm{C}_{2} \mathrm{O}_{4}{ }^{2-}$ are used to deposit $\mathrm{Ca}^{2+}, \mathrm{Mg}^{2+}$ and $\mathrm{Mn}^{2+}$ from this acidic vanadium-bearing solution, $\mathrm{V}(\mathrm{V})$ will be reduced to $\mathrm{V}(\mathrm{IV})$, resulting in larger consumption of reagent and complexity in purification operation because the reduced V(IV) needs to be re-oxidized before entering the consequent vanadium precipitation procedure.

$\mathrm{F}^{-}$is feasible to react with $\mathrm{Ca}^{2+}$ and $\mathrm{Mg}^{2}$ under weakly acidic conditions, producing $\mathrm{CaF}_{2}$ and $\mathrm{MgF}_{2}$ with smaller solubility product constants, so as to separate $\mathrm{Ca}^{2+}$ and $\mathrm{Mg}^{2+}$ from $\mathrm{V}(\mathrm{V})$. Using fluorides to remove calcium and magnesium in acidic solution has been studied in purification of manganese sulfate solution [36,37], nickel sulfate electrolyte [38] and zinc sulfate solution [39] but has not been reported in the purification of vanadiumbearing solution.

Presently, the main methods for removing $\mathrm{Mn}^{2+}$ from aqueous solution include anodic oxidation, potassium permanganate oxidation [40], calcium hypochlorite oxidation, sodium hypochlorite oxidation, oxygen oxidation, ozone oxidation [41], solvent extraction and adsorption [42,43]. Since in the process of $\mathrm{Mn}^{2+}$ oxidized by electrode, products of $\mathrm{MnO}_{4}{ }^{-}$ and $\mathrm{MnO}_{2}$ appear simultaneously, the reaction ending point for this method is difficult to control and the current efficiency is low [44]. Potassium permanganate can remove $\mathrm{Mn}^{2+}$ through oxidizing $\mathrm{Mn}^{2+}$ as $\mathrm{MnO}_{2}$ in an acidic medium, but the accurate additional amount of potassium permanganate is hard to calculate and the new impurity of $\mathrm{K}^{+}$is introduced. Similarly, calcium hypochlorite and sodium hypochlorite oxidations are also not applicable owning to the introduction of $\mathrm{Cl}^{-}$and $\mathrm{Na}^{+}$. Solvent extraction and adsorption are mainly adopted to treat low concentrations of $\mathrm{Mn}^{2+}$ in wastewater. The rate for oxygen oxidation is slow and it requires the $\mathrm{pH}$ value of solution to be higher than 8.00-8.50 [45]. The mixed gas of $\mathrm{SO}_{2}$ and $\mathrm{O}_{2}$ [46] can efficiently remove $\mathrm{Mn}^{2+}$ from solution at $\mathrm{pH}$ higher than 5.00, but at the same time, $\mathrm{V}(\mathrm{V})$ is reduced as $\mathrm{V}(\mathrm{IV})$ by $\mathrm{SO}_{2}$. Ozone can oxidize the $\mathrm{Mn}^{2+}$ to $\mathrm{MnO}(\mathrm{OH})_{2}$ and $\mathrm{MnO}_{4}{ }^{-}$, so the reaction ending point is also difficult to control, leading to $\mathrm{Mn}^{2+}$ and $\mathrm{Mn}^{7+}$ coexisting in the solution, which brings side effects on the quality of products of vanadium precipitation. Ammonium persulfate oxidizes $\mathrm{Mn}^{2+}$ to $\mathrm{MnO}_{2}$ without any new impurity introduced; hence, it may be suitable to remove $\mathrm{Mn}^{2+}$ from the acidic vanadium-bearing solution.

\subsection{Process Route for Purification of the Acidic Vanadium-Bearing Solution}

As stated above, $\mathrm{Al}^{3+}$ starts to hydrolyze and precipitate at a lower $\mathrm{pH}$ value and improving the $\mathrm{pH}$ value could accelerate agglomeration of the silicic acid and translation into gel precipitation. Therefore, neutralization is used to remove $\mathrm{Al}$ and $\mathrm{Si}$ under a weakly acidic situation.

The common fluorides used to remove $\mathrm{Ca}^{2+}$ and $\mathrm{Mg}^{2+}$ from an acidic aqueous media include $\mathrm{NaF}, \mathrm{KF}$ and $\mathrm{NH}_{4} \mathrm{~F}$. Introduction of $\mathrm{Na}^{+}$and $\mathrm{K}^{+}$will not only increase the contents of $\mathrm{Na}_{2} \mathrm{O}$ and $\mathrm{K}_{2} \mathrm{O}$ contained in the product of vanadium pentoxide but will also not be conducive to recycling of the mother liquid, hence, the soluble fluoride salt $\mathrm{NH}_{4} \mathrm{~F}$ and a prepared fluoride salt of $\mathrm{MnNH}_{4} \mathrm{~F}_{3}$ were selected to remove $\mathrm{Ca}^{2+}$ and $\mathrm{Mg}^{2+}$ from the acidic vanadium-bearing solution.

The longer the purification operational route of vanadium-bearing solution is, the higher the vanadium loss is. In order to reduce the vanadium loss, removing $\mathrm{Al}$ and $\mathrm{Si}$ by neutralization and precipitating $\mathrm{Ca}^{2+}$ and $\mathrm{Mg}^{2+}$ by fluoride were combined into one operation procedure, that is, while the fluoride was added, the $\mathrm{pH}$ value of the solution 
was adjusted to remove $\mathrm{Al}$ and $\mathrm{Si}$. After impurities of $\mathrm{Al}, \mathrm{Si}, \mathrm{Ca}$ and $\mathrm{Mg}$ were removed, $\mathrm{Mn}^{2+}$ was precipitated by ammonium persulfate oxidation.

\section{Experimental}

The acidic vanadium-bearing solution, as shown in Table 1, was from vanadium extraction with calcified roasting followed by the dilute acid leaching process. The chemical reagents used, like $\mathrm{NH}_{4} \mathrm{~F}, \mathrm{MnSO}_{4} \times \mathrm{H}_{2} \mathrm{O}, \mathrm{NH}_{4} \mathrm{OH}, \mathrm{H}_{2} \mathrm{SO}_{4},\left(\mathrm{NH}_{4}\right)_{2} \mathrm{SO}_{4}$ and $\left(\mathrm{NH}_{4}\right)_{2} \mathrm{~S}_{2} \mathrm{O}_{8}$, were all of analytical grade, from Sinopharm Chemical Reagent Co., Ltd. The brand of flocculant polyacrylamide $\left(\left[\mathrm{CH}_{2} \mathrm{CH}\left(\mathrm{CONH}_{2}\right)\right]_{n}\right)$ was Hushi. The filter aid of diatomaceous earth (DA-1) was from Shenyang Xinjiuwang Trading Co., Ltd. Deionized water was used in all of the purification experiments. The purification experiments were carried out in a thermostatic water bath (HH-4, China Changzhou Sino Instrument Co., LTD, Changzhou, China).

A stated volume of vanadium-bearing solution was added into a three-necked flask. When the target temperature was reached, fluorine salt was added at a specific molar ratio and then the stirring started. During the purification process, the $\mathrm{pH}$ values of solution were adjusted by ammonia hydroxide or dilute sulfuric acid. When the reaction ended, the flocculant polyacrylamide was added, stirring for $5 \mathrm{~min}$, and then the solution was let stand for a period. After filtration, the filtrate was collected, and its volume was recorded. The concentrations of $\mathrm{Ca}, \mathrm{Mg}, \mathrm{Al}$ and $\mathrm{Si}$ in the filtrate were measured by ICP-OES (Optima 4300DV, PerkinElmer Company, Waltham, Massachusetts, USA) and the concentration of $\mathrm{V}$ was determined by titration of ammonium ferrous sulfate. Based on these measured data, the removals of $\mathrm{Ca}, \mathrm{Mg}, \mathrm{Al}$ and $\mathrm{Si}$, and the loss of $\mathrm{V}$ were calculated. Ammonium persulfate was added at a certain excess coefficient into the above filtrate of $200 \mathrm{~mL}$ to oxidize and precipitate $\mathrm{Mn}^{2+}$.

In this paper, firstly, effects of $\mathrm{pH}$ value and temperature on the removal of $\mathrm{Al}, \mathrm{Si}$ and loss of $\mathrm{V}$ during the purification process with the neutralization method were studied to determine an appropriate $\mathrm{pH}$ range for purification operation. Then, the performances of $\mathrm{NH}_{4} \mathrm{~F}$ and $\mathrm{MnNH}_{4} \mathrm{~F}_{3}$ to remove impurities were compared and influences of parameters like stirring speed, adding amount, $\mathrm{pH}$ value, temperature, reaction time and filter aid on the purification efficiency were investigated. After the $\mathrm{Ca}, \mathrm{Mg}, \mathrm{Al}$ and $\mathrm{Si}$ were removed from the acidic vanadium-bearing solution, ammonium persulfate was added to oxidize and precipitate $\mathrm{Mn}^{2+}$ from the solution, and the feasibility of this method was assessed through comprehensively analyzing the effects of $\mathrm{pH}$ value, adding amount of ammonium persulfate and temperature on the removal of $\mathrm{Mn}$ and the loss of $\mathrm{V}$.

Every purification experiment was repeated twice, and another one or more times will be added if the difference of results obtained by these two repeated experiments is beyond a certain range, so the final result is the average value of data from at least two repeated experiments.

After the vanadium-bearing solution was purified, the vanadium contained in the purified solution was concentrated and precipitated with ammonium sulfate. The precipitation product was characterized by XRD (X-ray diffraction, X'Pert Pro MPD, PAnalytical B.V., Almelo, Netherlands) and SEM-EDS (Scanning electron microscope-Energy dispersive spectrometer, SSX-550, Shimadzu Corporation, Kyoto, Japan), and analyzed by a thermal gravimetric analyzer (STA409CD, NETZSCH, Selb, Germany) to determine an appropriate heating temperature for preparation of vanadium pentoxide. Vanadium pentoxide was obtained after the precipitation product was heated at a stated temperature for a certain period. The vanadium pentoxide was measured by XRF (X-ray fluorescence spectroscopy, ZSXPrimus IV, Rigaku, Japan) and ICP-OES and characterized by XRD and SEM-EDS. 


\section{Results and Discussion}

\subsection{Performance of Neutralization Precipitation to Remove Si and Al}

Under conditions of temperature of $65{ }^{\circ} \mathrm{C}$, stirring rate of $200 \mathrm{rpm}$ and stirring time of $20 \mathrm{~min}$, the effect of the $\mathrm{pH}$ value within $\mathrm{pH} 4.00$ to 4.50 on the removal of aluminum was as shown in Figure 1. The $\mathrm{pH}$ value of solution was adjusted by ammonium hydroxide.

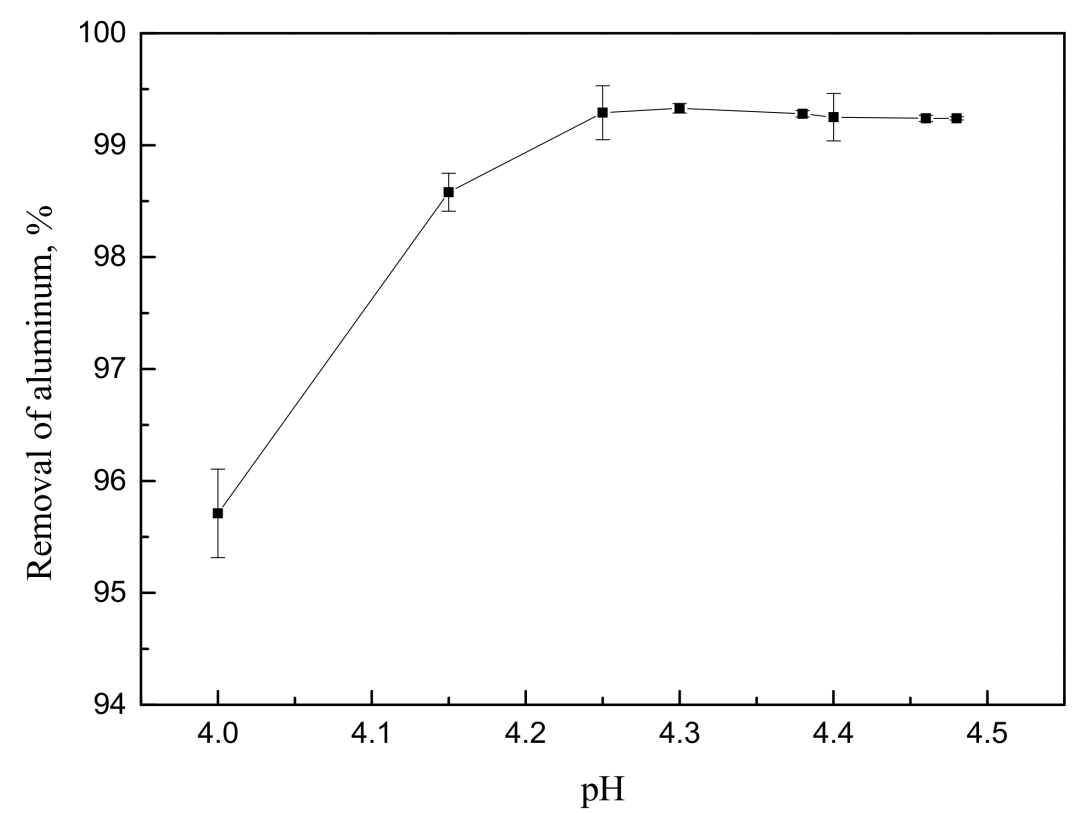

Figure 1. Effect of the $\mathrm{pH}$ value on the removal of aluminum.

Because the theoretical starting $\mathrm{pH}$ for $\mathrm{Al}^{3+}$ at a concentration of $0.001 \mathrm{~mol} \cdot \mathrm{L}^{-1}$ to hydrolyze and precipitate is 4.04 , the chosen $\mathrm{pH}$ range starts from $\mathrm{pH} 4.00$. As shown in Figure 1, when the $\mathrm{pH}$ value is improved from the initial value of 2.58 to 4.00 , the removal of aluminum reaches over $95 \%$. Further improving the $\mathrm{pH}$ value to 4.25 , the removal of aluminum increases from $95.7 \%$ to $99.3 \%$, and then the residual aluminum concentration in the solution almost keeps constant as the $\mathrm{pH}$ continues to increase. These results indicate that if neutralization is used to remove $\mathrm{Al}^{3+}$, the residual aluminum concentration can be lowered to $10 \mathrm{mg} \cdot \mathrm{L}^{-1}$ as the solution $\mathrm{pH}$ is raised to 4.00 .

The influence of $\mathrm{pH}$ on the removal of silicon at 65 and $80{ }^{\circ} \mathrm{C}$ was also investigated. During the whole process, ammonium hydroxide was added drop by drop to adjust the $\mathrm{pH}$ value at stirring speed of $200 \mathrm{rpm}$ for $20 \mathrm{~min}$, and the results are presented by Figure 2 and Table 3.

Obviously, the $\mathrm{pH}$ value has a great effect on the removal of $\mathrm{Si}$ and the loss of $\mathrm{V}$ when the temperature is controlled at $65^{\circ} \mathrm{C}$. As the $\mathrm{pH}$ value increases from 4.00 to 4.70 , the removal of Si goes up from $45 \%$ to $65 \%$, and unfortunately, the corresponding loss of $\mathrm{V}$ increases as well, from $17.8 \%$ to $33.4 \%$. When the temperature is raised to $80{ }^{\circ} \mathrm{C}$, the removal of Si slightly fluctuates at around $55 \%$ over the $\mathrm{pH}$ ranging from 4.50 to 5.20 , while the vanadium loss rises from $53.7 \%$ to $61.1 \%$. The larger vanadium loss at $\mathrm{pH}$ higher than 5.0 lies in the generation of undissolved vanadate through reactions between impurity ions like $\mathrm{Ca}^{2+}, \mathrm{Mg}^{2+}, \mathrm{Mn}^{2+}$ and vanadium ions. Additionally, as more ammonium hydroxide is added, the concentration of ammonium ion in solution increases and it is more likely for ammonium vanadate to form, especially at higher temperature, consequently resulting in a dramatic increase in the loss of vanadium. Hence, it is very important to control the $\mathrm{pH}$ value of solution within a proper range during the process of separating the impurities of $\mathrm{Si}$ and $\mathrm{Al}$ from the acidic vanadium-bearing solution. 


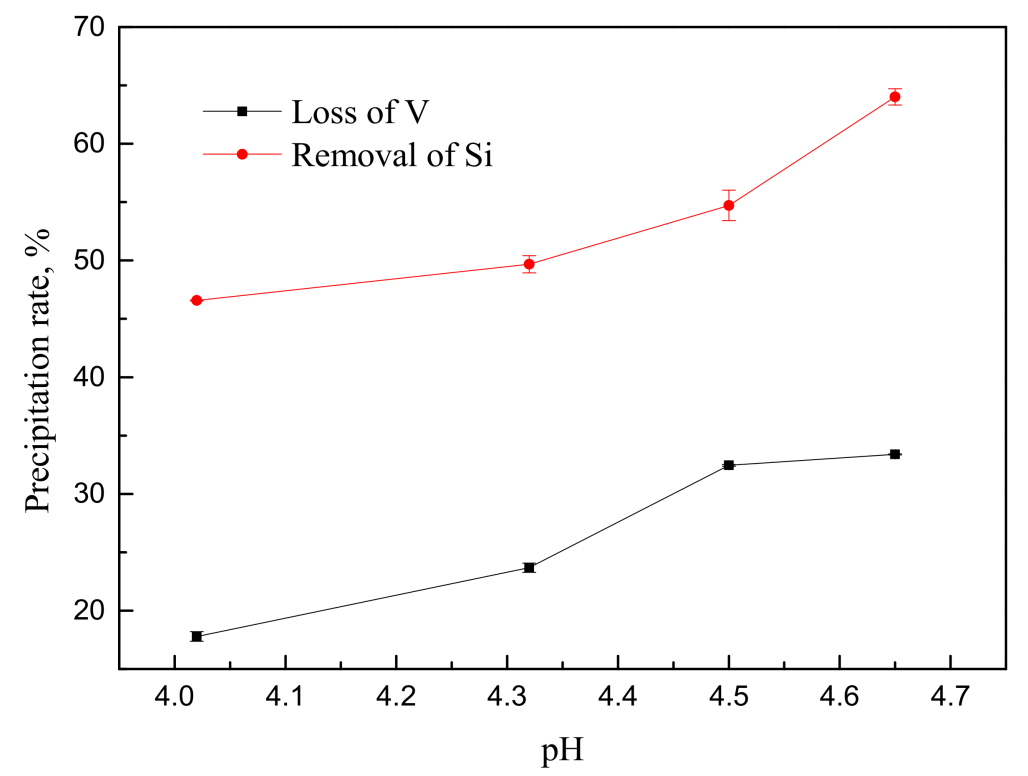

Figure 2. Effect of $\mathrm{pH}$ value on the removal of silicon and the loss of vanadium at $65^{\circ} \mathrm{C}$.

Table 3. Effect of $\mathrm{pH}$ value on the removal of silicon and the loss of vanadium at $80{ }^{\circ} \mathrm{C}$.

\begin{tabular}{cccc}
\hline \multirow{2}{*}{ Precipitation Rate, \% } & pH \\
\cline { 2 - 4 } & $\mathbf{4 . 5 0}$ & $\mathbf{4 . 6 0}$ & $\mathbf{5 . 2 0}$ \\
\hline $\mathrm{Si}$ & 55.1 & 58.5 & 55.1 \\
$\mathrm{~V}$ & 53.7 & 55.5 & 61.1 \\
\hline
\end{tabular}

\subsection{Comparison between $\mathrm{NH}_{4} \mathrm{~F}$ and $\mathrm{MnNH}_{4} \mathrm{~F}_{3}$}

The precipitant of $\mathrm{NH}_{4} \mathrm{~F}$ was added into the vanadium solution at a molar ratio, $n\left(\mathrm{NH}_{4} \mathrm{~F}\right) / n(\mathrm{Ca}+\mathrm{Mg})$, of 2.0 and temperature of $65^{\circ} \mathrm{C}$, and purification efficiency is shown by Figure 3. In order to decrease the loss of $\mathrm{V}$, the dilute sulfuric acid was used to adjust the $\mathrm{pH}$ value constantly at $4.50 \pm 0.10$.

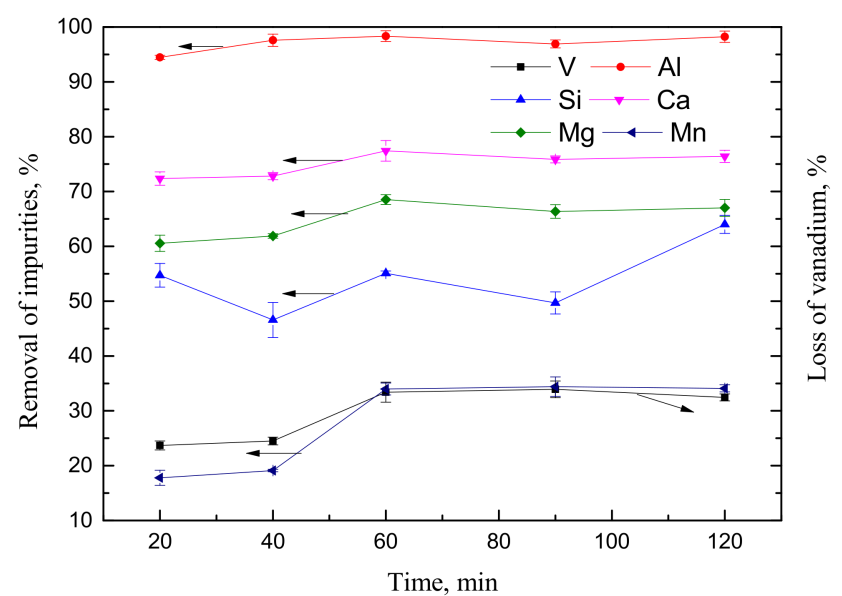

Figure 3. Purification efficiency of the vanadium-bearing solution with $\mathrm{NH}_{4} \mathrm{~F}$.

It can be seen from Figure 3 that when reaction time is extended to $60 \mathrm{~min}$, the removals of $\mathrm{Ca}, \mathrm{Mg}$ and $\mathrm{Al}$ are up to $77.4 \%, 68.5 \%$ and $98.3 \%$, respectively. The corresponding residual concentrations for $\mathrm{Ca}, \mathrm{Mg}$ and $\mathrm{Al}$ are 230,500 and $3.3 \mathrm{mg} \cdot \mathrm{L}^{-1}$. As for the impurity of $\mathrm{Si}$, its removal fluctuates around $55 \%$, which lies in the fact that the precipitation of $\mathrm{Si}$ is caused by an increase in solution $\mathrm{pH}$ after $\mathrm{NH}_{4} \mathrm{~F}$ is added rather than reaction with $\mathrm{NH}_{4} \mathrm{~F}$. 
The removal of Mn goes up to $33 \%$ as the time is increased to $60 \mathrm{~min}$, while the loss of $\mathrm{V}$ appears in the same trend, reaching $34 \%$ in $60 \mathrm{~min}$. In conclusion, $\mathrm{NH}_{4} \mathrm{~F}$ can effectively remove impurities of $\mathrm{Ca}$ and $\mathrm{Mg}$ from the acidic vanadium-bearing solution, while almost all of $\mathrm{Al}$ and partial Si precipitate simultaneously due to the increase in aqueous $\mathrm{pH}$ value, but the loss of vanadium is higher, with about $23 \%$ vanadium precipitating in the first $20 \mathrm{~min}$, and after purification, the slurry is hard to filter.

The precipitant of $\mathrm{MnNH}_{4} \mathrm{~F}_{3}$, a white powder, was prepared through reaction between $\mathrm{MnSO}_{4} \times \mathrm{H}_{2} \mathrm{O}$ and $\mathrm{NH}_{4} \mathrm{~F}$, with a molar ratio of $1: 7$, reaction temperature of $70{ }^{\circ} \mathrm{C}$ and time of $20 \mathrm{~min}$. The reaction product was filtered and washed several times to remove free ions of $\mathrm{NH}_{4}{ }^{+}$and $\mathrm{SO}_{4}{ }^{2-}$, and then was dried at $80{ }^{\circ} \mathrm{C}$ for $120 \mathrm{~min}$. The chemical analysis result of this obtained powder showed that the mass ratio of $\mathrm{F}$ to Mn was 1.0, and its XRD (X-ray diffraction) is shown by Figure 4. Based on the results of chemical analysis and XRD, it is known that the white powder was mainly composed of $\mathrm{Mn}\left(\mathrm{NH}_{4}\right) \mathrm{F}_{3}$. In subsequent experiments, this white powder precipitant is considered as $\mathrm{Mn}\left(\mathrm{NH}_{4}\right) \mathrm{F}_{3}$ only to simplify calculation.

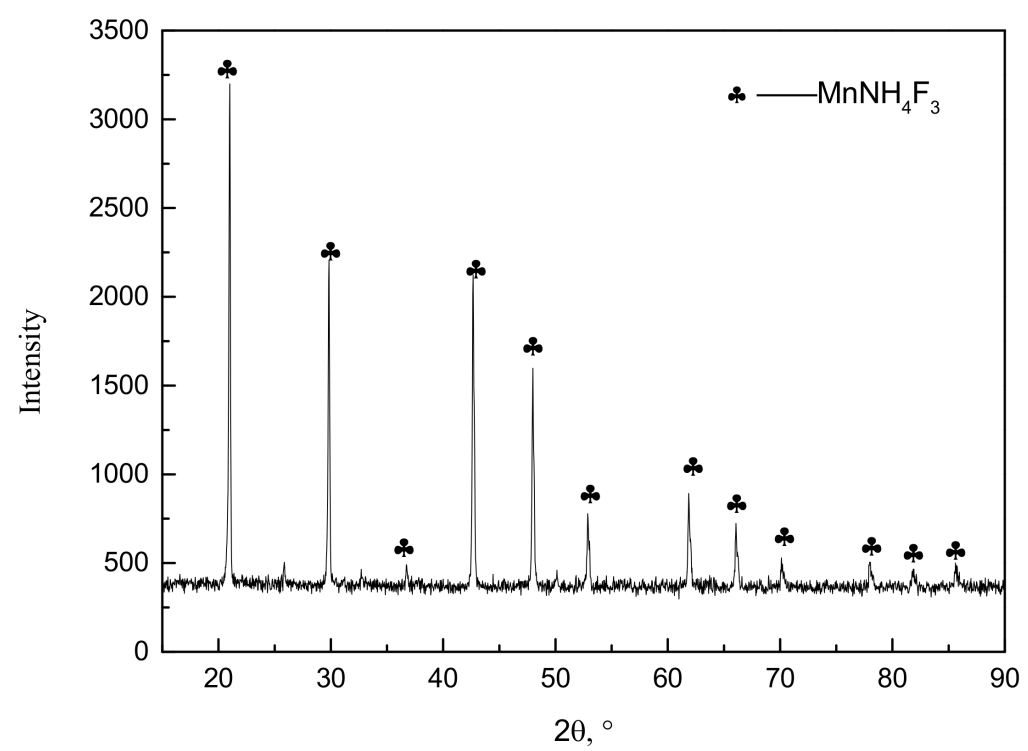

Figure 4. X-ray diffraction (XRD) pattern of the prepared precipitant.

The precipitant of $\mathrm{MnNH}_{3} \mathrm{~F}_{3}$ was added into the vanadium-bearing solution at molar ratio of $n(2 \mathrm{~F}) / n(\mathrm{Ca}+\mathrm{Mg})$ of 1.0 , temperature of $65^{\circ} \mathrm{C}$ with a stirring speed of $200 \mathrm{rpm}$, and its purification efficiency is shown by Figure 5 .

After the precipitant $\mathrm{MnNH}_{4} \mathrm{~F}_{3}$ is added, the aqueous $\mathrm{pH}$ value increases but keeps lower than 4.20. As shown in Figure 5, the precipitant $\mathrm{MnNH}_{4} \mathrm{~F}_{3}$ performs best in removing $\mathrm{Ca}^{2+}$ and $\mathrm{Mg}^{2+}$. The removals of $\mathrm{Ca}$ and $\mathrm{Mg}$ reach $74.1 \%$ and $58.8 \%$ respectively, in $10 \mathrm{~min}$, and then almost level off as the reaction time is extended, indicating that the purification process runs fast. Within the whole reaction time range, the removal of $\mathrm{Ca}$ is higher than that of $\mathrm{Mg}$, which lies in the reason that $\mathrm{Ca}^{2+}$ is more feasible to react with $\mathrm{F}^{-}$than $\mathrm{Mg}^{2+}$, thermodynamically. If the $\mathrm{F}^{-}$is insufficient in the solution, it will combine with $\mathrm{Ca}^{2+}$ prior to $\mathrm{Mg}^{2+}$.

Since $\mathrm{NH}_{4}{ }^{+}$is contained in the precipitant $\mathrm{MnNH}_{4} \mathrm{~F}_{3}$, adding $\mathrm{MnNH}_{4} \mathrm{~F}_{3}$ results in an increase in the $\mathrm{pH}$ of vanadium-bearing solution, up to 4.15 , which promotes the hydrolysis of $\mathrm{Al}^{3+}$ to form precipitate of $\mathrm{Al}(\mathrm{OH})_{3}$. As a result, adding $\mathrm{MnNH}_{4} \mathrm{~F}_{3}$ can remove impurity of $\mathrm{Al}$ simultaneously. The removal of $\mathrm{Al}$ is over $95 \%$ in the first $10 \mathrm{~min}$, but as the reaction time is furthered, the removal of $\mathrm{Al}$ decreases slightly due to a drop in aqueous solution $\mathrm{pH}$ value caused by slow ammonium volatilization from the solution at $65^{\circ} \mathrm{C}$. When the stirring time is increased to $60 \mathrm{~min}$, the $\mathrm{pH}$ value declines to 3.73 . 


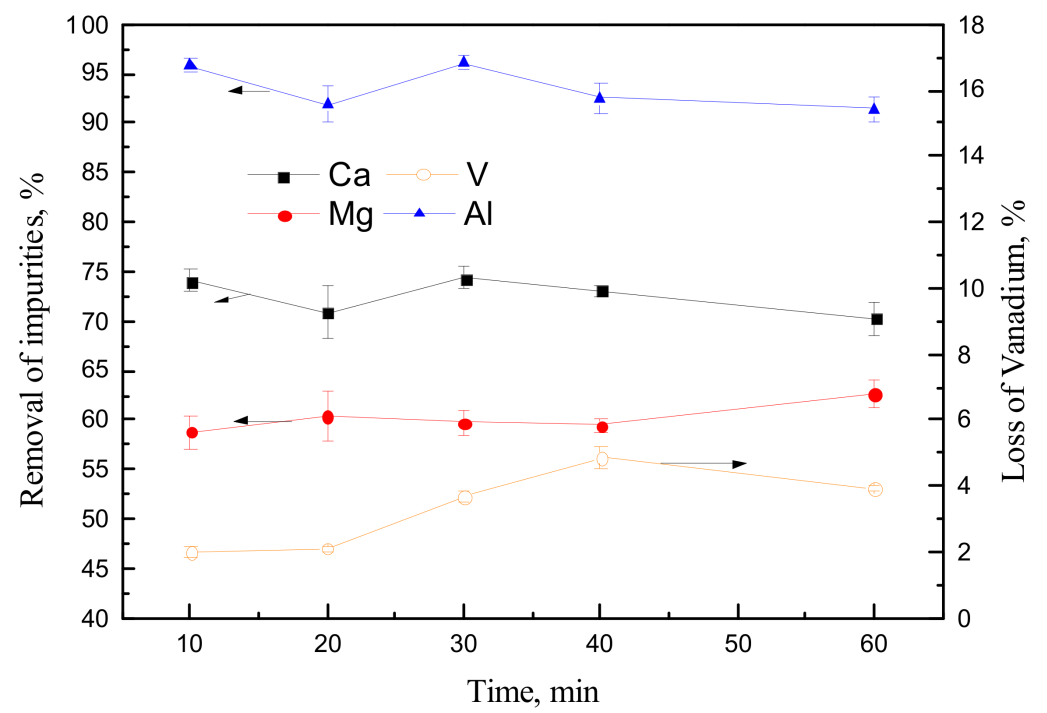

Figure 5. Purification efficiency of the vanadium-bearing solution using the prepared precipitant of $\mathrm{MnNH}_{4} \mathrm{~F}_{3}$.

The loss of $\mathrm{V}$ is still lower than $5 \%$ during the whole purification process with $\mathrm{MnNH}_{4} \mathrm{~F}_{3}$. When using $\mathrm{NH}_{4} \mathrm{~F}$ to purify the vanadium-bearing solution, one mole $\mathrm{F}^{-}$ is introduced together with one mole $\mathrm{NH}_{4}{ }^{+}$, but in terms of $\mathrm{MnNH}_{4} \mathrm{~F}_{3}$, one mole $\mathrm{F}^{-}$ brings $1 / 3$ mole $\mathrm{NH}_{4}{ }^{+}$, so in comparison with $\mathrm{NH}_{4} \mathrm{~F}, \mathrm{MnNH}_{4} \mathrm{~F}_{3}$ makes the solution $\mathrm{pH}$ increase less, and then the loss of vanadium is lower. Additionally, because the precipitant $\mathrm{MnNH}_{4} \mathrm{~F}_{3}$ is insoluble in the acidic vanadium-bearing solution, and then free $\mathrm{F}^{-}$ is fewer, reactions between $\mathrm{Ca}^{2+}, \mathrm{Mg}^{2+}$ and $\mathrm{F}^{-}$mainly happen on the surface of the precipitant, resulting in little vanadium being absorbed and co-precipitated by the reaction products. Besides, the products of $\mathrm{CaF}_{2}, \mathrm{MgF}_{2}$ and $\mathrm{MnF}_{2}$ are nearly un-dissolvable in the vanadium-bearing solution, leading to little free $\mathrm{F}^{-}$contained in the solution, which does not obviously corrode the reactor. Moreover, after purification with $\mathrm{MnNH}_{4} \mathrm{~F}_{3}$, the obtained slurry is easier to filter than that with $\mathrm{NH}_{4} \mathrm{~F}$.

\subsection{Effecting Factors of the Purification with $\mathrm{MnNH}_{4} \mathrm{~F}_{3}$}

\subsubsection{Effect of Stirring Speed}

Under the conditions that $\mathrm{MnNH}_{4} \mathrm{~F}_{3}$ was added according to a molar ratio $n(2 \mathrm{~F}) /$ $n(\mathrm{Ca}+\mathrm{Mg})$ of 1.0 at $65{ }^{\circ} \mathrm{C}$ and the purification process lasted for $10 \mathrm{~min}$, the effect of stirring speed on removals of $\mathrm{Ca}$ and $\mathrm{Mg}$ are as shown by Figure 6. During the whole purification process, the $\mathrm{pH}$ value of solution was not adjusted with other acid or alkaline.

As displayed in Figure 6, the stirring speed greatly impacts the removals of $\mathrm{Ca}$ and $\mathrm{Mg}$. Since $\mathrm{MnNH}_{4} \mathrm{~F}_{3}$ is little dissolved in the solution, the reactions between $\mathrm{MnNH}_{4} \mathrm{~F}_{3}$ and $\mathrm{Ca}^{2+}$ and $\mathrm{Mg}^{2+}$ happen on the surface of $\mathrm{MnNH}_{4} \mathrm{~F}_{3}$ particles. Dispersion of the $\mathrm{MnNH}_{4} \mathrm{~F}_{3}$ particles greatly depends on the stirring speed. When the stirring intensity is not enough for the particles to disperse in the solution uniformly, some of them will go down to the bottom of the reactor without thorough contact with $\mathrm{Ca}^{2+}$ and $\mathrm{Mg}^{2+}$, leading to lower removals of impurities. Increasing the stirring speed promotes the dispersion of $\mathrm{MnNH}_{4} \mathrm{~F}_{3}$ particles and improves mass transfer of the solution system, and meanwhile, decreases the loss of vanadium caused by absorption of precipitation products of $\mathrm{Ca}, \mathrm{Mg}$ and $\mathrm{Al}$ as well. As displayed by Figure 6, when the stirring speed increases from 50 to $150 \mathrm{rpm}$, the removals of $\mathrm{Ca}$ and $\mathrm{Mg}$ rise remarkably. After that, increasing the stirring speed does not accelerate removal of impurities of $\mathrm{Ca}$ and $\mathrm{Mg}$ from the solution. As the stirring speed is increased to over $200 \mathrm{rpm}$, the removals of Ca and $\mathrm{Mg}$ nearly level off, and it seems that $200 \mathrm{rpm}$ is enough for the precipitant particles to disperse and thoroughly contact impurity ions in the solution. 


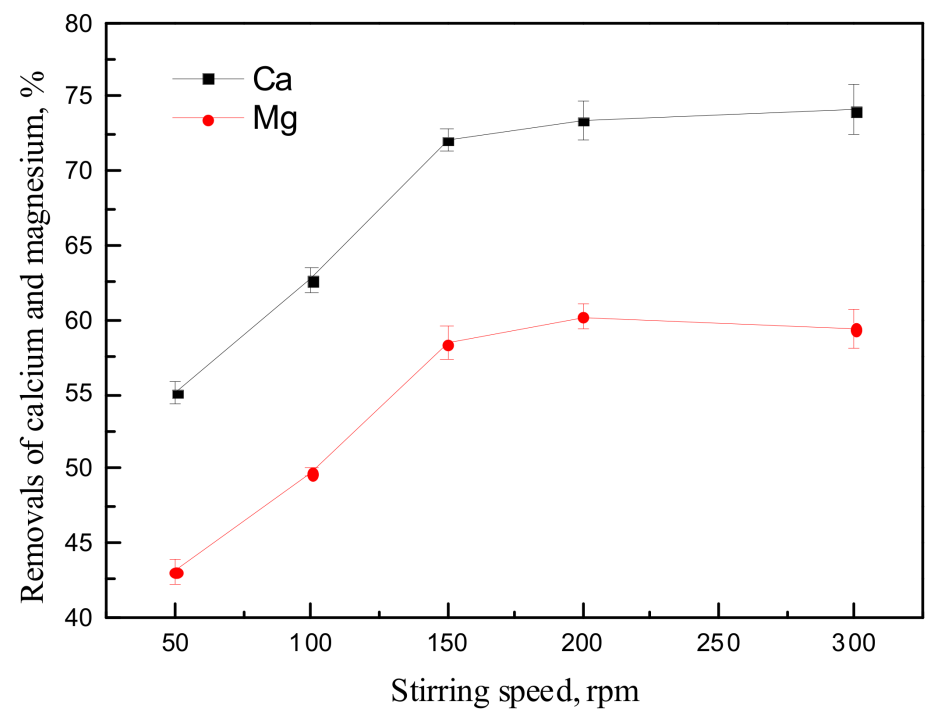

Figure 6. Effect of stirring speed on the calcium and magnesium removals.

\subsubsection{Effect of Adding Amount of $\mathrm{MnNH}_{4} \mathrm{~F}_{3}$}

The effect of the adding amount coefficient, $a(a=n(2 \mathrm{~F}) / n(\mathrm{Ca}+\mathrm{Mg}))$, on the purification efficiency was studied when other parameters $\times \times$ were fixed at a temperature of $30{ }^{\circ} \mathrm{C}$, reaction time of $10 \mathrm{~min}$ and the stirring speed of $200 \mathrm{rpm}$, and the $\mathrm{pH}$ value was not adjusted with other reagents. The relationships between the adding amount coefficient and the removals of $\mathrm{Ca}, \mathrm{Mg}$ and $\mathrm{Al}$ are illustrated by Figure 7 .

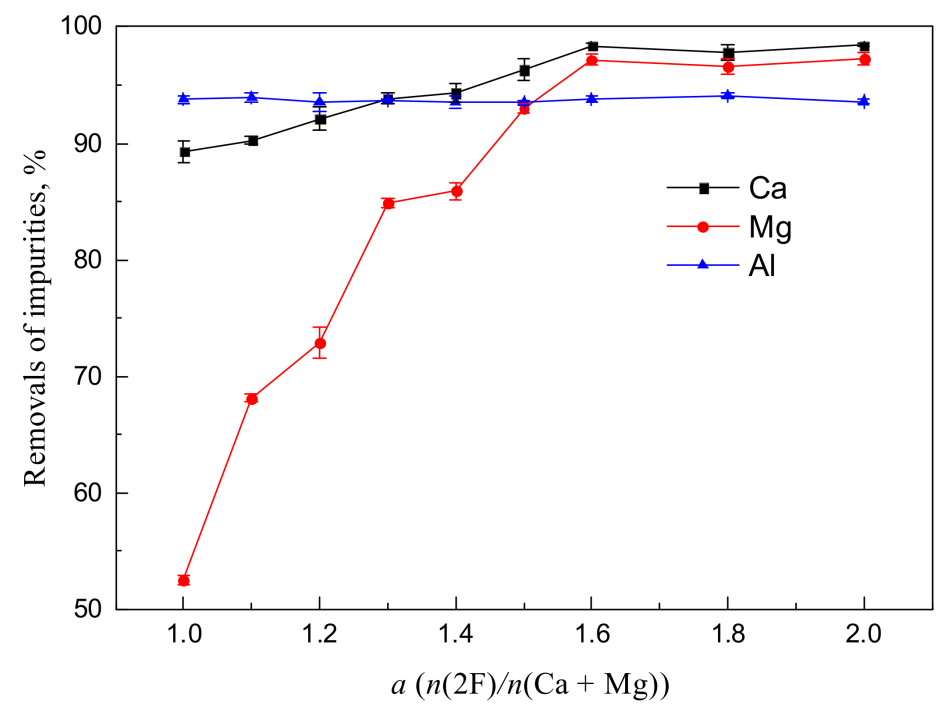

Figure 7. Effect of adding dosage on impurity removal.

When $a$ equals 1.0, which is the theoretical value for complete purification reactions, removals of $\mathrm{Ca}^{2+}$ and $\mathrm{Mg}^{2+}$ go up to $89.3 \%$ and $52.5 \%$ respectively, and the residual concentrations of $\mathrm{Ca}^{2+}$ and $\mathrm{Mg}^{2+}$ in the solution are still high, up to 109 and $755 \mathrm{mg} \cdot \mathrm{L}^{-1}$. Raising the adding amount can obviously promote removal of impurities of $\mathrm{Ca}$ and $\mathrm{Mg}$, especially for the removal of $\mathrm{Mg}$. The removals of $\mathrm{Ca}$ and $\mathrm{Mg}$ increase with increase in $a$ value until it is up to 1.6, at which point the removals of $\mathrm{Ca}$ and $\mathrm{Mg}$ reach $98.4 \%$ and $97.2 \%$, and then the concentrations of $\mathrm{Ca}$ and $\mathrm{Mg}$ left in the solution are 16.4 and $44.6 \mathrm{mg} \cdot \mathrm{L}^{-1}$, respectively. Within the whole range of $a$ changing from 1.0 to 2.0, the removal of $\mathrm{Al}$ keeps at $93.5-94.0 \%$, and the concentration of $\mathrm{Al}$ in the solution is decreased from 200 to $13 \mathrm{mg} \cdot \mathrm{L}^{-1}$. 


\subsubsection{Effect of the $\mathrm{pH}$ Value of Solution}

In the above experiments, the $\mathrm{pH}$ value of solution was not adjusted with other acid or alkaline during the purification process. In order to investigate relationships between the $\mathrm{pH}$ value and the removals of $\mathrm{Ca}, \mathrm{Mg}$ and $\mathrm{Al}$, and the loss of $\mathrm{V}$, the $\mathrm{pH}$ value of solution was kept constant with ammonium hydroxide or dilute sulfuric acid after the precipitant $\mathrm{MnNH}_{4} \mathrm{~F}_{3}$ was added. Other experimental parameters were fixed (temperature $=30^{\circ} \mathrm{C}$, time $=10 \mathrm{~min}$, stirring speed $=200 \mathrm{rpm}$ and adding amount coefficient $=1.6$ ). The results are displayed in Figure 8.

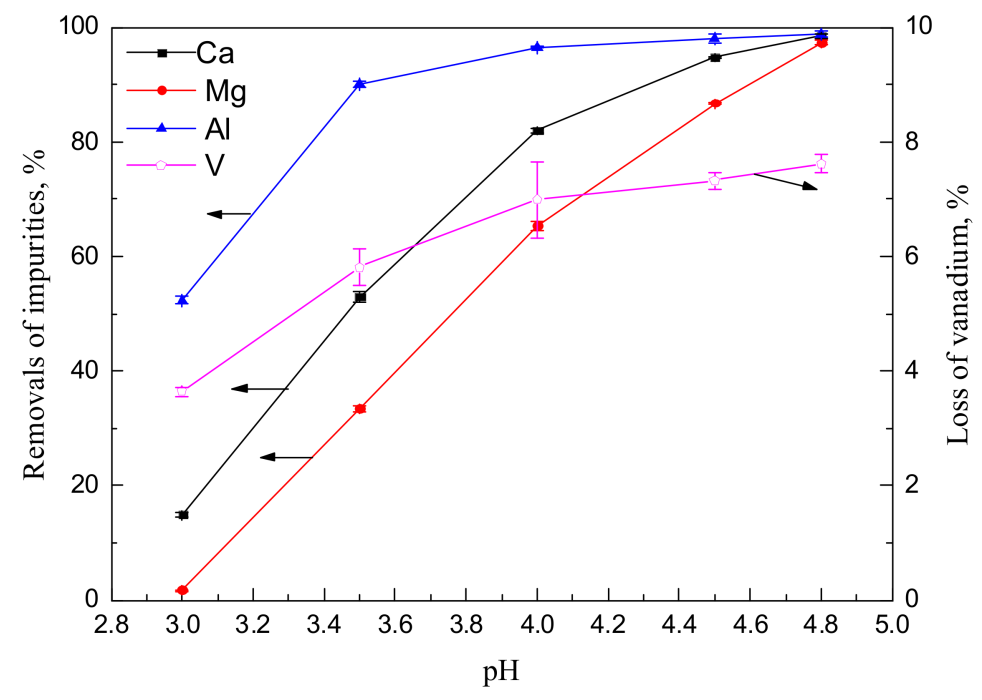

Figure 8. Effect of the $\mathrm{pH}$ value on the removals of impurities and the loss of vanadium.

From $\mathrm{pH} 3.00$ to $\mathrm{pH} 4.80$, changes in removals of impurities and loss of vanadium are both sharp. At $\mathrm{pH} 3.00$, the removals of $\mathrm{Ca}, \mathrm{Mg}$ and $\mathrm{Al}$ are lower, only being $14.8 \%$, $1.66 \%$ and $52.3 \%$, respectively. As the $\mathrm{pH}$ increases, the removals accordingly go up, while the loss of $\mathrm{V}$ increases as well. When the $\mathrm{pH}$ value is constant at 4.8 during the whole purification process, $98.4 \%$ of $\mathrm{Ca}, 97.3 \%$ of $\mathrm{Mg}$ and $98.8 \%$ of $\mathrm{Al}$ are separated from the solution, and the remaining concentrations of those impurities go down to 16.0, 43.7 and $3.00 \mathrm{mg} \cdot \mathrm{L}^{-1}$, which meets the requirements for the concentration of impurities in the next step of APV (ammonium polyvanadate) preparation. At $\mathrm{pH} 4.80,7.62 \%$ of $\mathrm{V}$ is lost. As we know, in the purification process of vanadium-bearing solution, the loss of $\mathrm{V}$ is an important indicator to evaluate the purification efficiency. According to the results shown in Figure 8, $\mathrm{pH} 4.50 \pm 0.05$ is chosen as an appropriate $\mathrm{pH}$ value for purification of the acidic vanadium-bearing solution, additionally, at which little free HF is produced to erode the reactor.

\subsubsection{Effect of Temperature and Time}

Figure $9 \mathrm{a}-\mathrm{d}$ show the effect of the temperature, ranging from 30 to $80^{\circ} \mathrm{C}$, and time on purification efficiency under the conditions that the adding amount coefficient of $\mathrm{MnNH}_{4} \mathrm{~F}_{3}$ was 1.6, the stirring speed was set at $200 \mathrm{rpm}$ and the $\mathrm{pH}$ value of solution was kept constant at $4.50 \pm 0.05$.

Generally, raising the temperature promotes the reaction rate. In the first $3 \mathrm{~min}$, removal of $\mathrm{Ca}$ increases with increase in temperature. The removals of $\mathrm{Ca}$ at 30,50 and $65{ }^{\circ} \mathrm{C}$ reach $60.8 \%, 69.3 \%$ and $70.2 \%$, respectively. Instead, the removal of $65.95 \%$ at $80{ }^{\circ} \mathrm{C}$ is lower than those at 50 and $65^{\circ} \mathrm{C}$. This is because the precipitant of $\mathrm{MnNH}_{4} \mathrm{~F}_{3}$ dissolves less with increase in temperature, which results in less free $\mathrm{F}^{-}$at higher temperatures, and then the reactions between the $\mathrm{F}^{-}$and impurity irons of $\mathrm{Ca}^{2+}$ and $\mathrm{Mg}^{2+}$ are limited during purification at $80{ }^{\circ} \mathrm{C}$, leading to lower removals of $\mathrm{Ca}^{2+}$ and $\mathrm{Mg}^{2+}$. 

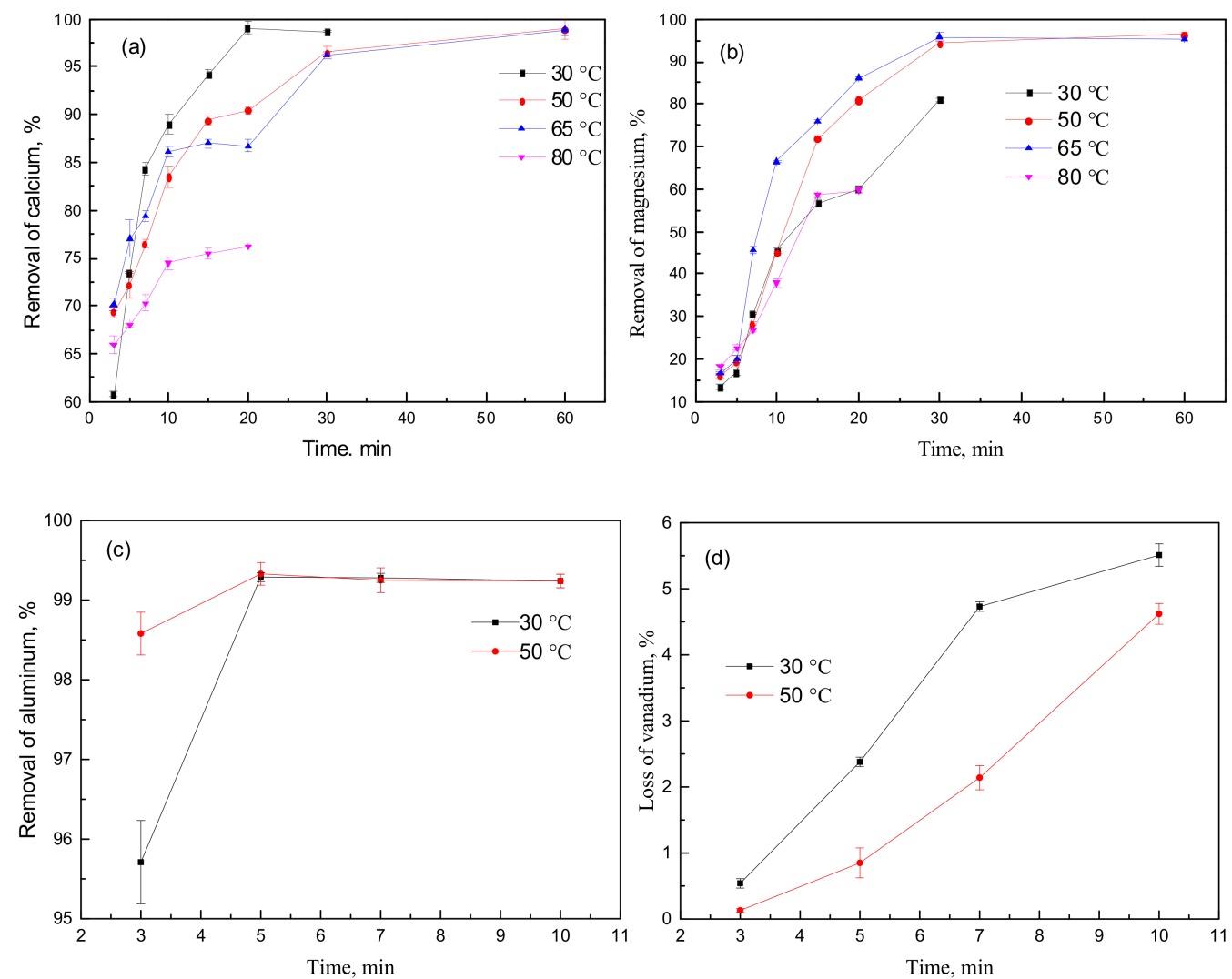

Figure 9. Effect of temperature and time on the removal of calcium (a), removal of magnesium (b), removal of aluminum (c) and loss of vanadium (d).

As the reaction time is increased, the removal of calcium goes up. At $30^{\circ} \mathrm{C}$, the removal of Ca rises fast in the first $20 \mathrm{~min}$. When the purification process proceeds for 5 and $7 \mathrm{~min}$, the removal at $30^{\circ} \mathrm{C}$ exceeds those at 50 and $65^{\circ} \mathrm{C}$, respectively. After reaction for $20 \mathrm{~min}$, the reaction reaches balance and the removal of $\mathrm{Ca}$ is up to the maximum of 99.1\%; meanwhile, the remaining concentration of Ca in the solution is down to $9 \mathrm{mg} \cdot \mathrm{L}^{-1}$. Similarly, after the reaction lasting for $12 \mathrm{~min}$, the impurity of Ca is removed more at $50{ }^{\circ} \mathrm{C}$ than that at $60^{\circ} \mathrm{C}$. When the reaction time is furthered to $30 \mathrm{~min}$, the removals of $\mathrm{Ca}$ at 50 and $65{ }^{\circ} \mathrm{C}$ both level off, achieving $96.5 \%$ and $96.2 \%$, respectively. At the same time, the retained contents of $\mathrm{Ca}$ in the solution are 35.6 and $38.7 \mathrm{mg} \cdot \mathrm{L}^{-1}$, respectively. When the time is increased to $60 \mathrm{~min}$, the removals at 50 and $65^{\circ} \mathrm{C}$ both go up to around $98.9 \%$.

In comparison with Figure $9 \mathrm{~b}$, the removal of $\mathrm{Mg}$ obviously increases more slowly than that of $\mathrm{Ca}$ in the first $10 \mathrm{~min}$, which results from the fact that the formation of $\mathrm{CaF}_{2}$ is more feasible than the formation of $\mathrm{MgF}_{2}$, thermodynamically, and the free $\mathrm{F}^{-}$prefers to react with $\mathrm{Ca}^{2+}$. Due to the limitation in solubility of $\mathrm{MnNH}_{4} \mathrm{~F}_{3}$, the removal of $\mathrm{Mg}$ at $80{ }^{\circ} \mathrm{C}$ rises slowly with increase in reaction time. The removals of $\mathrm{Mg}$ at 65 and $50{ }^{\circ} \mathrm{C}$ are higher than that at $30^{\circ} \mathrm{C}$, both constantly reaching around $95 \%$ after $30 \mathrm{~min}$ of reaction, and at the same time, the remaining concentration of $\mathrm{Mg}^{2+}$ in the solution is $80.0 \mathrm{mg} \cdot \mathrm{L}^{-1}$.

The removal of $\mathrm{Al}$ increases with increase in stirring time. When the reaction time is over $5 \mathrm{~min}$, more than $99 \%$ of aluminum is removed. High temperature is beneficial to formation of $\mathrm{Al}(\mathrm{OH})_{3}$ and removing $\mathrm{Al}^{3+}$ from the solution. It can be seen from Figure $9 \mathrm{c}$ that when the reaction temperatures are set at 30 and $50{ }^{\circ} \mathrm{C}$, the concentrations of aluminum left in the solution are both lower than $10 \mathrm{mg} \cdot \mathrm{L}^{-1}$ after reaction for $3 \mathrm{~min}$. As the reaction time is increased from 3 to $10 \mathrm{~min}$, the loss of $\mathrm{V}$ increases as well, which is owing to the rising adsorption of vanadium caused by more precipitations of $\mathrm{CaF}_{2}, \mathrm{MgF}_{2}$ and $\mathrm{Al}(\mathrm{OH})_{3}$ produced with an increase in reaction time. In the first $10 \mathrm{~min}$, more $\mathrm{CaF}_{2}$ and $\mathrm{MgF}_{2}$ are generated at $30{ }^{\circ} \mathrm{C}$ than these at $50{ }^{\circ} \mathrm{C}$, so the loss of $\mathrm{V}$ at $30^{\circ} \mathrm{C}$ is higher. In addition, crystals of $\mathrm{CaF}_{2}$ and $\mathrm{MgF}_{2}$ with lower adsorption capacity may be produced at higher 
temperature. Considering the effects of reaction temperature and time on the removals of $\mathrm{Ca}, \mathrm{Mg}$ and $\mathrm{Al}$, and the loss of $\mathrm{V}$, the optimum operational temperature and time are chosen as $50^{\circ} \mathrm{C}$ and $30 \mathrm{~min}$, respectively.

\subsubsection{Effect of Flocculant and Filter Aid}

The precipitant $\mathrm{MnNH}_{4} \mathrm{~F}_{3}$ was added into $400 \mathrm{~mL}$ vanadium-bearing solution with an adding amount coefficient of 1.6 , and then the temperature was kept at $50{ }^{\circ} \mathrm{C}$ and the solution $\mathrm{pH}$ was adjusted to $4.50 \pm 0.05$. After the reaction lasting for $30 \mathrm{~min}$, the flocculant of polyacrylamide with a concentration of $0.0200 \mathrm{~g} \cdot \mathrm{L}^{-1}$ was introduced and the stirring was furthered for $5 \mathrm{~min}$. The effect of the amount of polyacrylamide added in the solution on the efficiency of purification is listed in Table 4.

Table 4. Effect of flocculant on the purification efficiency.

\begin{tabular}{ccccc}
\hline \multirow{2}{*}{ Adding Amount, $\mathbf{m L}$} & \multicolumn{4}{c}{ Removal, \% } \\
\cline { 2 - 5 } & $\mathbf{C a}$ & $\mathbf{M g}$ & $\mathbf{A l}$ & $\mathbf{V}$ \\
\hline 0 & 97.7 & 97.8 & 98.7 & 8.32 \\
4 & 97.8 & 96.9 & 99.0 & 4.27 \\
8 & 98.1 & 94.8 & 99.3 & 4.05 \\
\hline
\end{tabular}

It is well-known that flocculent can improve the settleability of the slurry. As shown in Table 4, adding flocculant can increase the removal of $\mathrm{Ca}$ and $\mathrm{Al}$, and obviously decrease the loss of $\mathrm{V}$, which is attributed to the fact that the flocculant promotes the settling velocity of precipitates of $\mathrm{Ca}$ and $\mathrm{Al}$, and then adsorption of vanadium is reduced. However, raising the amount of flocculant almost has no effect on the removals of $\mathrm{Ca}$ and $\mathrm{Al}$, while it further reduces the removal of Mg. Hence, we chose to add $1 \mathrm{~mL}$ of flocculant per $100 \mathrm{~mL}$ vanadium-bearing solution in the subsequent experiments.

It was found that the slurry was difficult to filter due to the colloids of silicic acid and aluminum hydroxide produced during the purification process. These colloids were likely to block the pores of filter paper and extended the filtration time. However, in the lab experiments, we discovered that using filter aid of diatomite to form a cake layer first and then filtering slurry could effectively reduce the filtration time by half.

\subsection{Mechanism of Purifying the Vanadium-Bearing Solution with $\mathrm{MnNH}_{4} \mathrm{~F}_{3}$}

As shown in Figure 4, the prepared impurity remover was mainly composed of $\mathrm{MnNH}_{4} \mathrm{~F}_{3}$, and its SEM-EDS analysis result is shown in Figure 10.

It can be seen from Figure 10 that the prepared impurity remover of $\mathrm{MnNH}_{2} \mathrm{~F}_{3}$ exists in cube crystal with an edge length of around $20 \mu \mathrm{m}$. This impurity remover is difficult to dissolve in the acidic vanadium-bearing solution, so after it is added, the stirring should be started immediately to prevent the remover from sinking to the bottom of the reactor, in order to ensure the remover contacts with impurity ions in the solution. In the perspective of thermodynamics, $\mathrm{F}^{-}$is more likely to react with $\mathrm{Ca}^{2+}$ and $\mathrm{Mg}^{2+}$ to generate $\mathrm{CaF}_{2}$ and $\mathrm{MgF}_{2}$, which are more difficult to dissolve in the solution, as shown by Equations (1) and (2), promoting further ionization of $\mathrm{MnNH}_{4} \mathrm{~F}_{3}$. Meanwhile, more $\mathrm{NH}_{4}{ }^{+}$ions are discharged in the progress of purification reactions and make the $\mathrm{pH}$ value increase, accelerating the hydrolysis of $\mathrm{Al}^{3+}$ and the coagulation of the silicic acid. Hence, the impurities of $\mathrm{Ca}, \mathrm{Mg}$, $\mathrm{Al}$ and $\mathrm{Si}$ are separated simultaneously from the vanadium-bearing solution at a $\mathrm{pH}$ lower than 4.50 .

$$
\begin{aligned}
2 \mathrm{~F}^{-}+\mathrm{Ca}^{2+} & =\mathrm{CaF}_{2}\left(K_{\mathrm{sp}, 25^{\circ} \mathrm{C}}=5.30 \times 10^{-9}\right) \\
2 \mathrm{~F}^{-}+\mathrm{Mg}^{2+} & =\mathrm{CaF}_{2}\left(K_{\mathrm{sp}, 25^{\circ} \mathrm{C}}=5.16 \times 10^{-11}\right)
\end{aligned}
$$




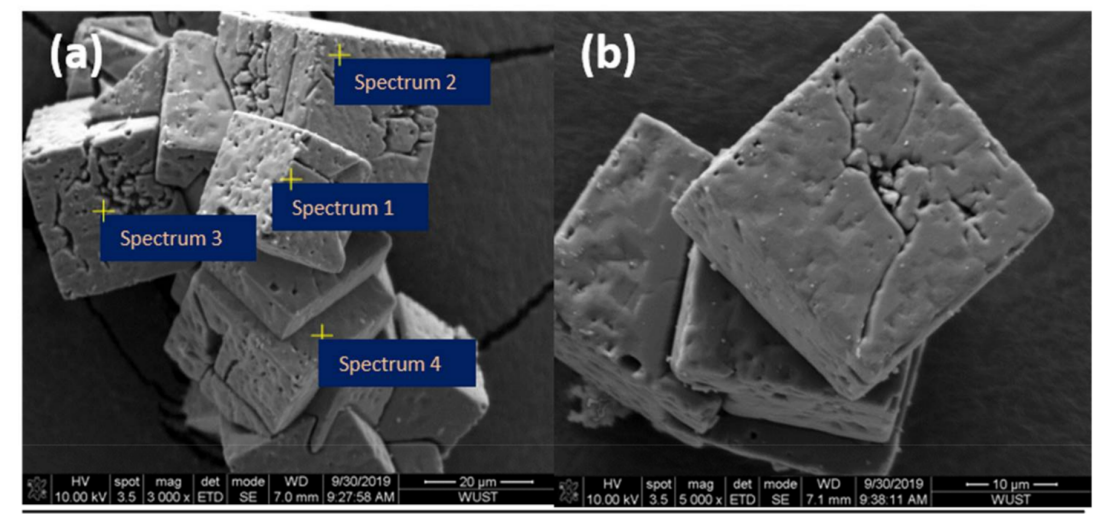

Element (in weight, \%)

\begin{tabular}{cccc}
\cline { 2 - 4 } Spectrum & $\mathrm{N}$ & $\mathrm{F}$ & $\mathrm{Mn}$ \\
\hline Spectrum 1 & 2.91 & 62.7 & 34.4 \\
Spectrum 2 & 1.88 & 62.0 & 36.1 \\
Spectrum 3 & 1.65 & 51.1 & 47.3 \\
Spectrum 4 & 1.92 & 57.2 & 40.9 \\
\hline
\end{tabular}

Figure 10. SEM-EDS analysis for the prepared impurity remover of $\mathrm{MnNH}_{4} \mathrm{~F}_{3}$, (a) magnification $\times 3000$, (b) magnification $\times 5000$.

After drying at $80{ }^{\circ} \mathrm{C}$ for $12 \mathrm{~h}$, the precipitation product was measured by $\mathrm{X}$-ray fluorescence (XRF) and the results are shown in Table 5 . The precipitation product was also characterized by XRD and SEM-EDS and the results are shown in Figures 11 and 12.

Table 5. X-ray fluorescence (XRF) analysis for the precipitate obtained during the purification with $\mathrm{MnNH}_{4} \mathrm{~F}_{3}$ (wt. \%).

\begin{tabular}{cccccccccc}
\hline $\mathbf{F}$ & $\mathbf{C a}$ & $\mathbf{M g}$ & $\mathbf{M n}$ & $\mathbf{A l}$ & $\mathbf{V}$ & $\mathbf{P}$ & $\mathbf{S i}$ & $\mathbf{F e}$ & Others \\
\hline 44.1 & 18.7 & 18.7 & 12.3 & 4.04 & 0.977 & 0.401 & 0.236 & 0.123 & 0.513 \\
\hline
\end{tabular}

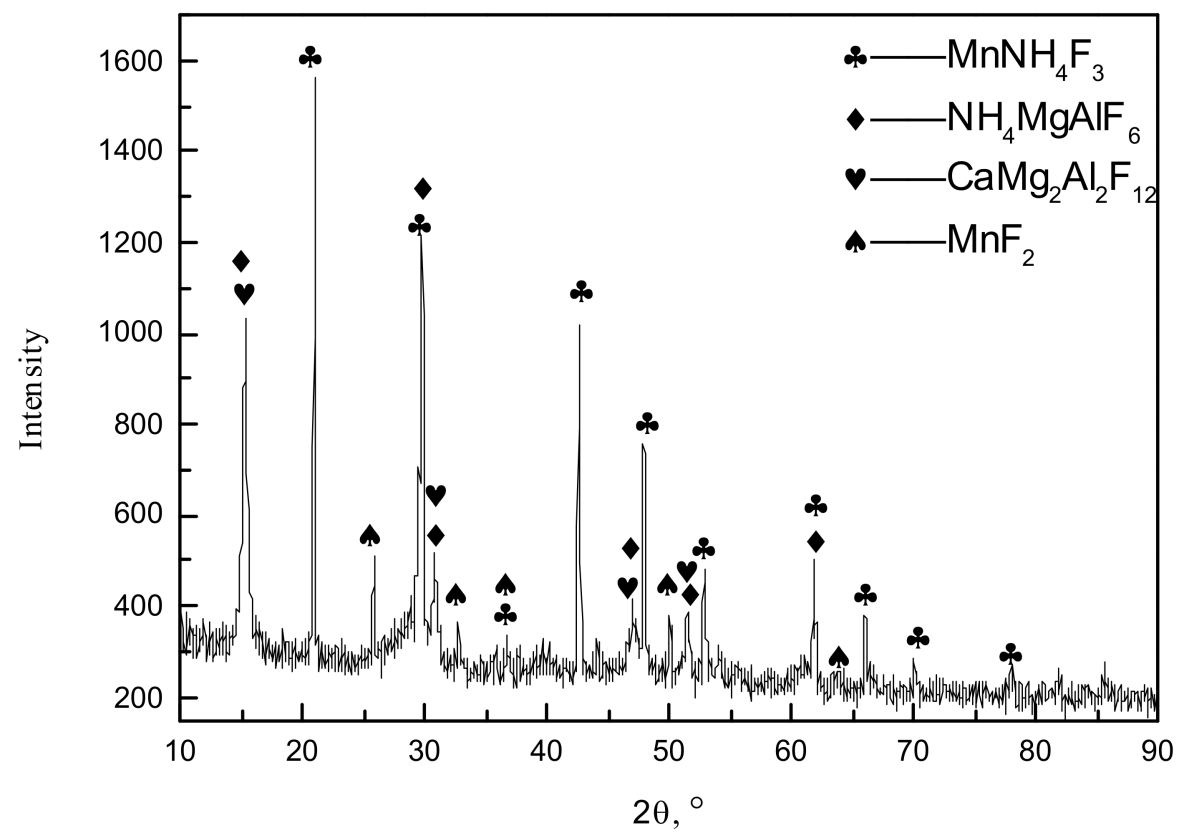

Figure 11. X-ray diffraction pattern for precipitation product obtained when the adding dosage of $\mathrm{MnNH}_{4} \mathrm{~F}_{3}$ was 1.6. 


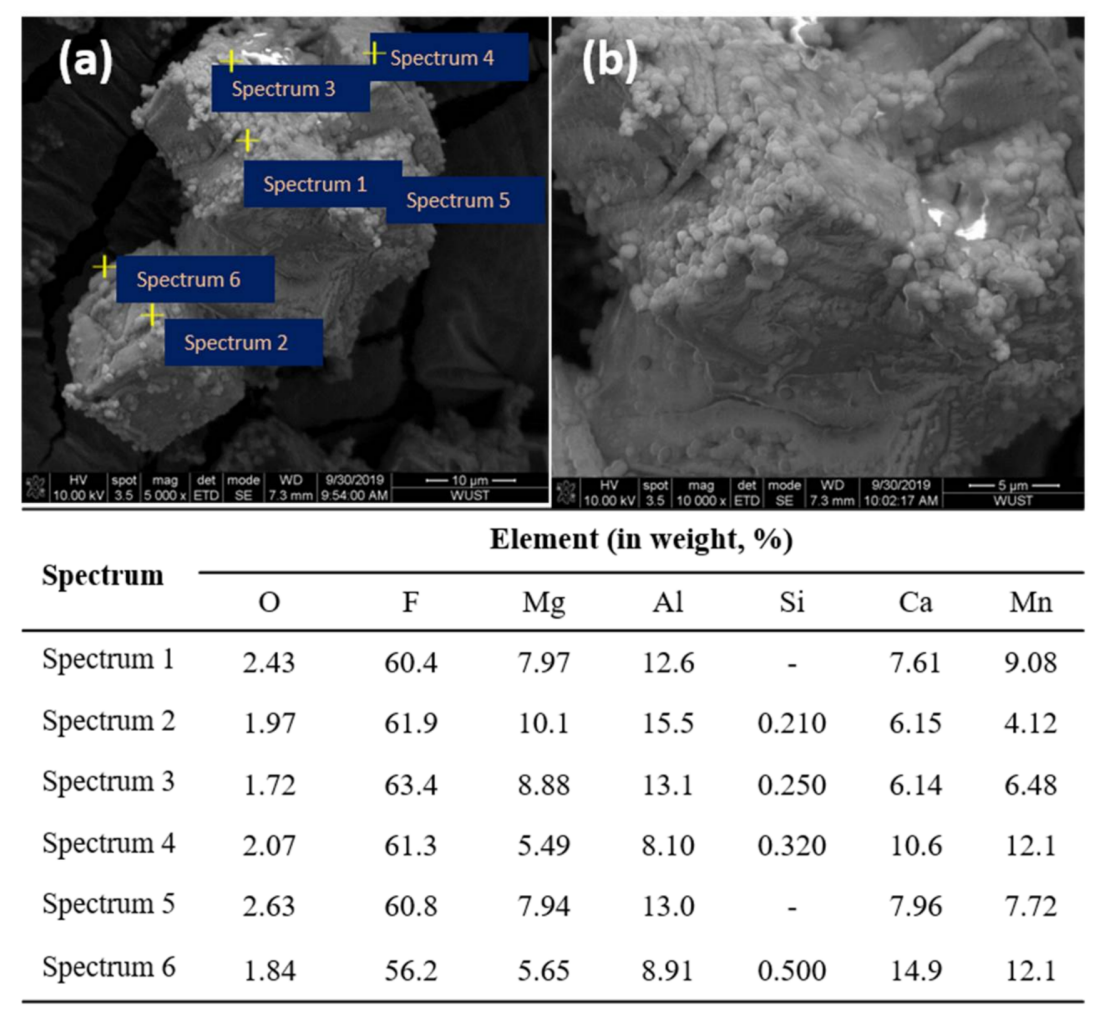

Figure 12. SEM-EDS analysis for the precipitate obtained during purification with $\mathrm{MnNH}_{4} \mathrm{~F}_{3}$, (a) magnification $\times 5000$, (b) magnification $\times 10,000$.

As shown by Table 5 and Figure 11, the precipitate is mainly composed of F, Ca, Mg, $\mathrm{Al}$ and $\mathrm{Mn}$ elements. Some compositions in this precipitation product exist in the form of $\mathrm{NH}_{4} \mathrm{MgAlF}_{6}, \mathrm{CaMg}_{2} \mathrm{Al}_{2} \mathrm{~F}_{12}$ and $\mathrm{MnF}_{2}$, and some exist in amorphous state, which appears as flocculated sediment during the purification and makes the slurry difficult to filter.

In comparison with Figure 10, it can be seen from Figure 12 that the cube crystals of $\mathrm{MnNH}_{2} \mathrm{~F}_{3}$ are wrapped by the precipitation products of impurity after purification. The remover of $\mathrm{MnNH}_{4} \mathrm{~F}_{3}$ is insoluble in the acidic vanadium-bearing solution, and free $\mathrm{F}^{-}$ was fewer. Reactions between $\mathrm{Ca}^{2+}, \mathrm{Mg}^{2+}$ and $\mathrm{F}^{-}$mainly happen on the surface of the remover, and then the reaction products directly attach to the surface of the remover of $\mathrm{MnNH}_{4} \mathrm{~F}_{3}$. Therefore, the vanadium loss caused by absorption and co-precipitation is lower when using $\mathrm{MnNH}_{4} \mathrm{~F}_{3}$ to purify the solution than that when using $\mathrm{NH}_{4} \mathrm{~F}$.

\subsection{Removing Impurity of $\mathrm{Mn}$ with Ammonium Persulfate}

Ammonium persulfate $\left(\mathrm{NH}_{4}\right)_{2} \mathrm{~S}_{2} \mathrm{O}_{8}$ is a strong oxidant, which can oxidize $\mathrm{Mn}^{2+}$ into precipitate of $\mathrm{MnO}_{2}$ in acidic solution and is often used to remove $\mathrm{Mn}^{2+}$ from the sulfuric acid solution system.

After removing $\mathrm{Ca}, \mathrm{Mg}$ and $\mathrm{Al}$ from the vanadium-containing solution through adding $\mathrm{MnNH}_{4} \mathrm{~F}_{3}$, the concentration of $\mathrm{Mn}^{2+}$ in the solution increased from 5.99 to $10.1 \mathrm{~g} \cdot \mathrm{L}^{-1}$. In this section, the feasibility of using ammonium persulfate oxidation to remove high concentrations of $\mathrm{Mn}^{2+}$ from the acidic vanadium-bearing solution was evaluated. The effects of temperature, adding coefficient of ammonium persulfate and $\mathrm{pH}$ value on the removal of $\mathrm{Mn}$ and the loss of $\mathrm{V}$ were investigated separately.

\subsubsection{Effect of Adding Coefficient of $\left(\mathrm{NH}_{4}\right)_{2} \mathrm{~S}_{2} \mathrm{O}_{8}$}

The adding coefficient refers to the molar ratio of $\left(\mathrm{NH}_{4}\right)_{2} \mathrm{~S}_{2} \mathrm{O}_{8}$ to $\mathrm{Mn}$. Under the conditions that the temperature was $90^{\circ} \mathrm{C}, \mathrm{pH}$ value of solution was 2.00 , stirring time was $3 \mathrm{~h}$ and the slurry was allowed to stand for $3 \mathrm{~h}$ after reaction ended, the effect of the adding coefficient of $\left(\mathrm{NH}_{4}\right)_{2} \mathrm{~S}_{2} \mathrm{O}_{8}$ on the removal of $\mathrm{Mn}$ and the loss of $\mathrm{V}$ is shown by Figure 13. 


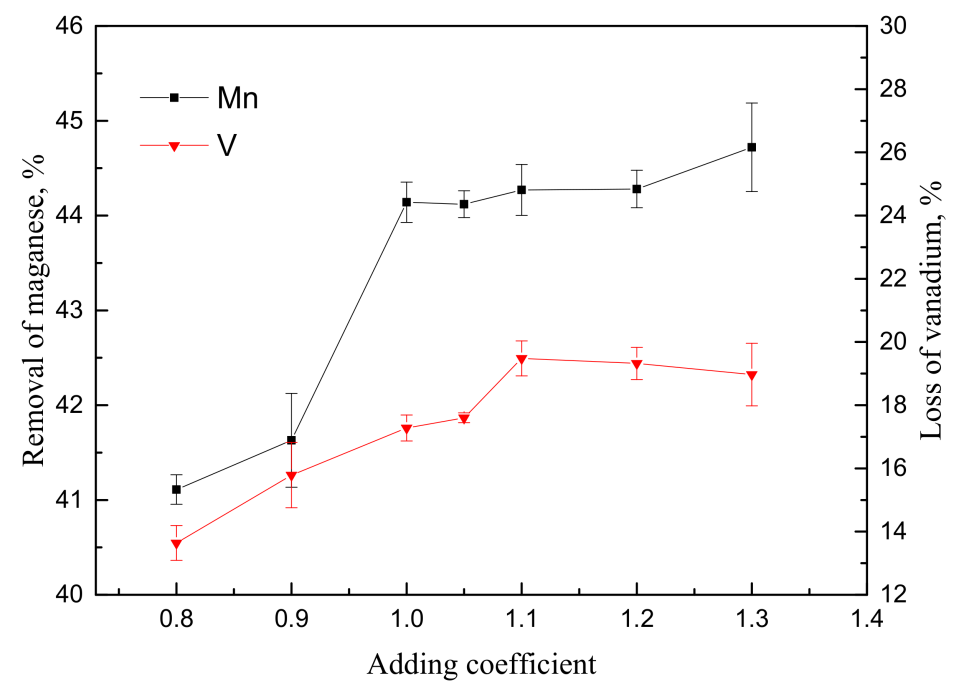

Figure 13. Effect of the adding coefficient of $\left(\mathrm{NH}_{4}\right)_{2} \mathrm{~S}_{2} \mathrm{O}_{8}$ on the removal of manganese and the loss of vanadium.

It can be seen from Figure 13 that as the adding coefficient increases from 0.8 to 1.0, the removal of $\mathrm{Mn}$ increases from $41.1 \%$ to $44.1 \%$, and when the ammonium persulfate is further increased, the removal of $\mathrm{Mn}$ increases slowly. Only $44.7 \%$ of $\mathrm{Mn}$ is removed when the adding coefficient is improved to 1.3. The loss of $\mathrm{V}$ increases as well with increasing the adding amount of ammonium persulfate. When the adding coefficient rises from 0.8 to 1.0 and to 1.1 , the corresponding loss of $\mathrm{V}$ goes up from $13.6 \%$ to $17.3 \%$ and to $19.5 \%$. It can be interpreted from the mechanism of removing $\mathrm{Mn}^{2+}$ with ammonium persulfate oxidation, that when more ammonium persulfate is added, the reaction product of hydrated manganese dioxide which has strong adsorption performance generates more, leading to a larger amount of vanadium settling together with the hydrated manganese dioxide. Besides, $\mathrm{NH}_{4}{ }^{+}$, which is introduced through adding ammonium persulfate, is likely to react with vanadate ions at high temperature to form precipitation of ammonium vanadate.

\subsubsection{Effect of Temperature}

The reaction parameters were fixed as the adding coefficient of 1.0, $\mathrm{pH}$ value of 2.00, reaction time of $3 \mathrm{~h}$ and standing time of $3 \mathrm{~h}$, and relationships between the reaction time and the removal of Mn and the loss of V are displayed by Figure 14.

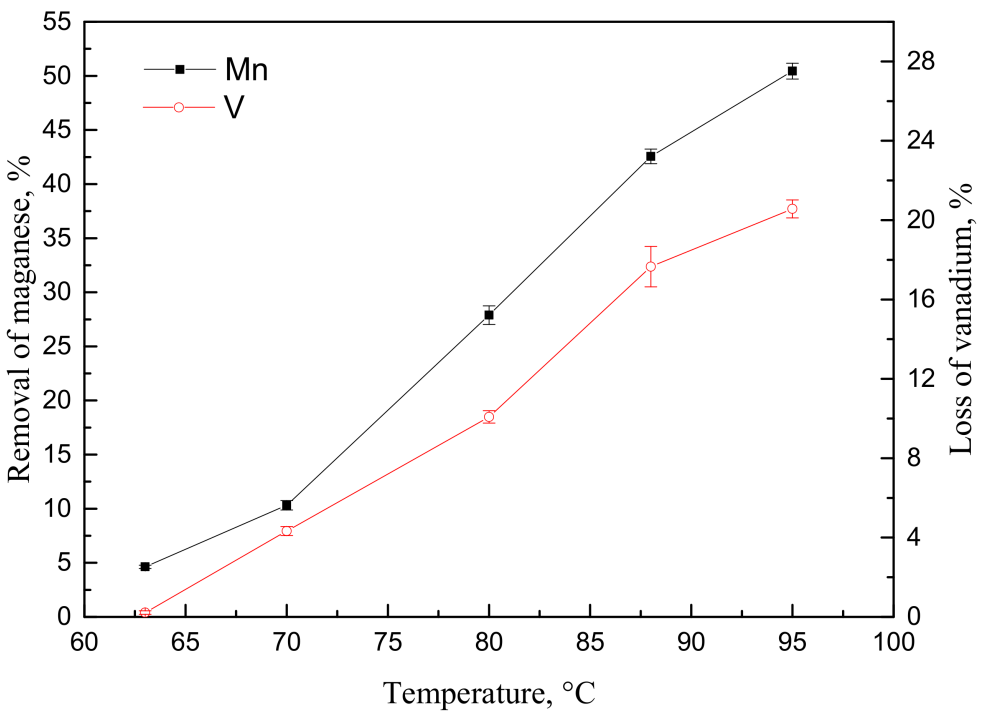

Figure 14. Effect of temperature on the removal of manganese and the loss of vanadium. 
As shown in Figure 14, the reaction time remarkably influences the removing efficiency of $\mathrm{Mn}$, and high temperature is beneficial for separating $\mathrm{Mn}$ from the vanadium-bearing solution. As the reaction temperature is improved from 63 to $95{ }^{\circ} \mathrm{C}$, the removal of Mn grows greatly, by around $45 \%$, from $4.63 \%$ to $50.4 \%$, while the loss of V obviously increases to $20.6 \%$ with the increase in temperature, which is due to the fact that more colloidal hydrated manganese dioxide is produced at higher temperatures. Hence, it is not appropriate to lower the concentration of $\mathrm{Mn}$ retained in the vanadium-bearing solution through only improving the temperature.

\subsubsection{Effect of $\mathrm{pH}$ Value of Solution}

The effect of the $\mathrm{pH}$ value of the solution on the removing efficiency of manganese is illustrated in Figure 15 when other reaction parameters were set to a temperature of $80^{\circ} \mathrm{C}$, adding coefficient of 1.0, stirring time of $3 \mathrm{~h}$ and standing time of $3 \mathrm{~h}$.

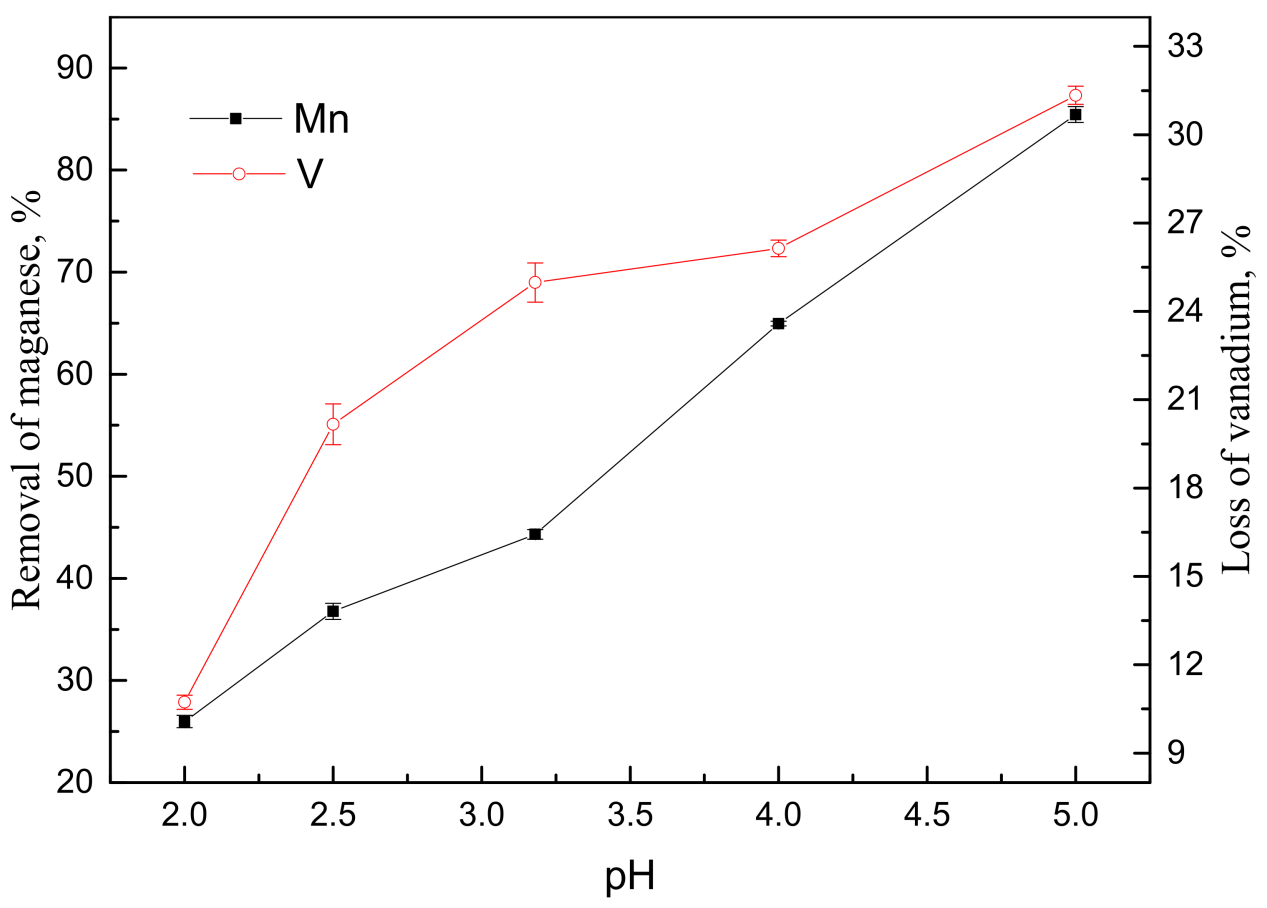

Figure 15. Effect of $\mathrm{pH}$ value of aqueous solution on the removal of manganese and the loss of vanadium.

Oxidation of $\mathrm{Mn}^{2+}$ by ammonium persulfate is dependent on the $\mathrm{pH}$ value of aqueous solution. As shown in Figure 14, the removal of Mn goes up sharply from $26.0 \%$ to $85.4 \%$ with increasing the $\mathrm{pH}$ value from 2.00 to 5.00 . Sulfuric acid is produced by the oxidation reaction between $\left(\mathrm{NH}_{4}\right)_{2} \mathrm{~S}_{2} \mathrm{O}_{8}$ and $\mathrm{Mn}^{2+}$, leading to a decrease in the $\mathrm{pH}$ of the solution system, so improving the $\mathrm{pH}$ value is conducive to the positive progress of the oxidation reaction, and more $\mathrm{Mn}^{2+}$ ions transform in precipitation of hydrated manganese dioxide. Similar to Figures 13 and 14, the loss of $\mathrm{V}$ changes in the same trend as the removal of $\mathrm{Mn}$ over the $\mathrm{pH}$ value increasing from 2.00 to 5.00 , and the loss of $\mathrm{V}$ is as high as $31.3 \%$ at a $\mathrm{pH}$ of 5.00 .

Figures 13-15 suggest that improving the reaction time, adding amount of ammonium persulfate and the $\mathrm{pH}$ value all accelerate the removal of $\mathrm{Mn}$. However, the higher the removal of $\mathrm{Mn}$, the higher the loss of $\mathrm{V}$. This is because the oxidation product of the hydrated manganese dioxide has good absorption performance, carrying a large amount of vanadium in its settlement process. Overall, the oxidation precipitation method with ammonium persulfate is not suitable to separate $\mathrm{Mn}$ from the vanadium-bearing solution with high concentrations of Mn. 
Generally, the manganese contained in the final product of vanadium pentoxide does not have an evident side effect on product quality and performance when the vanadium pentoxide is used to smelt normal vanadium iron or to prepare catalysts. In addition, our previous study suggests that using ammonium salt to precipitate vanadium from the solution can reduce the adverse influence of $\mathrm{Mn}$ on the grade of vanadium pentoxide, so the manganese left in the solution is not treated before the vanadium precipitation procedure.

\subsection{Vanadium Precipitation and Thermal Decomposition}

The concentrations of $\mathrm{V}$ and main impurities contained in the vanadium-bearing solution before and after purification are given in Table 6 .

Table 6. Concentrations of vanadium and main impurities contained in the vanadium-bearing solution $\left(\mathrm{g} \cdot \mathrm{L}^{-1}\right)$.

\begin{tabular}{ccccccccccc}
\hline Elements & $\mathbf{V}$ & $\mathbf{M n}$ & $\mathbf{S i}$ & $\mathbf{A l}$ & $\mathbf{C a}$ & $\mathbf{F e}$ & $\mathbf{M g}$ & $\mathbf{C r}$ & $\mathbf{T i}$ & $\mathbf{P}$ \\
\hline Before purification & 21.4 & 5.99 & 1.49 & 0.200 & 1.02 & 0.010 & 1.59 & 0.0100 & 0.00570 & 0.120 \\
\hline After purification & 19.8 & 10.1 & 0.670 & 0.00900 & 0.0330 & 0.00900 & 0.0790 & 0.0100 & 0.00400 & 0.0890 \\
\hline
\end{tabular}

After purification, the concentrations of $\mathrm{Ca}, \mathrm{Mg}$ and $\mathrm{Al}$ decreased to 33.0, 79.0 and $9.00 \mathrm{mg} \cdot \mathrm{L}^{-1}$ respectively, and only the concentration of $\mathrm{Mn}$ increased, which was caused by the reactions between $\mathrm{MnNH}_{4} \mathrm{~F}_{3}$ and $\mathrm{Ca}^{2+}$ and $\mathrm{Mg}^{2+}$ during the purification process.

Vanadium was concentrated and precipitated with $\left(\mathrm{NH}_{4}\right)_{2} \mathrm{SO}_{4}$ from the purified solution at initial $\mathrm{pH}$ of 2.00 and temperature of $95^{\circ} \mathrm{C}$, and precipitation efficiency was over $96 \%$. The XRD and SEM-EDS characterization for the product of vanadium precipitation are given by Figures 16 and 17.

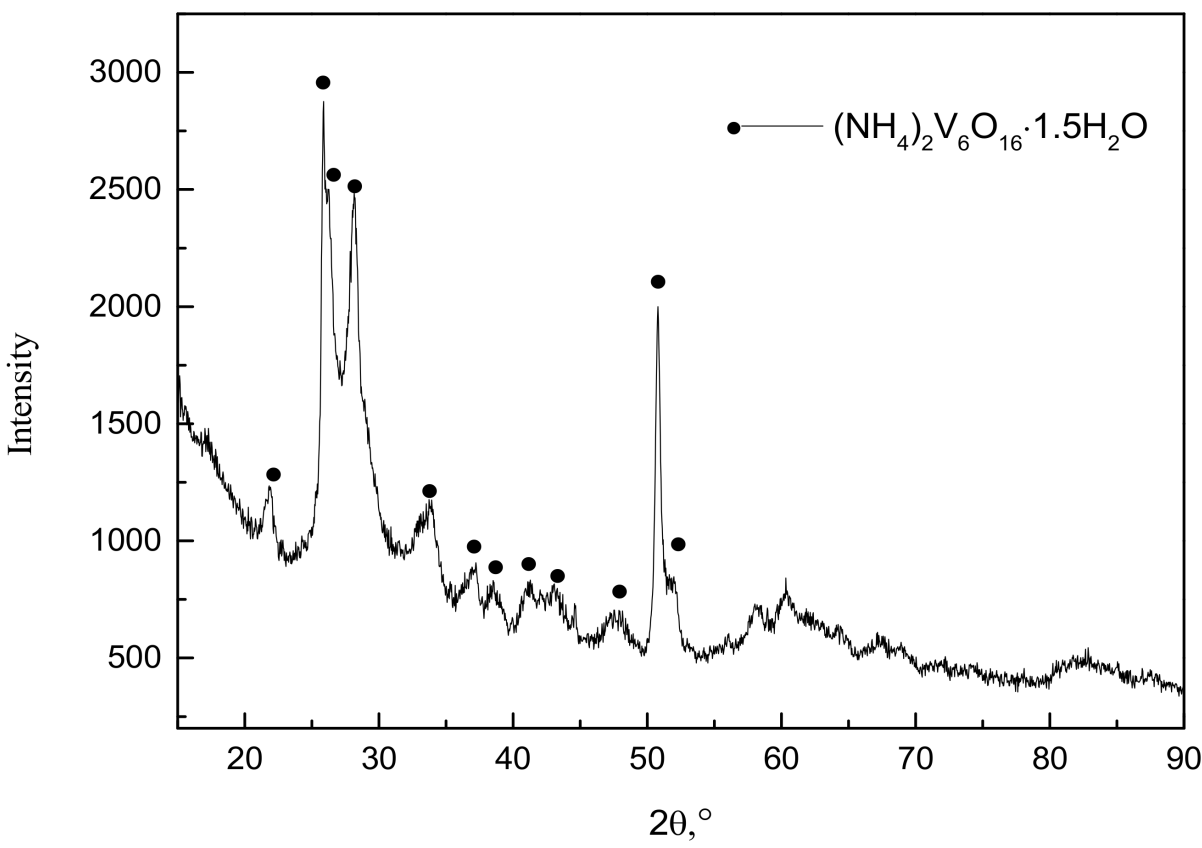

Figure 16. XRD pattern for the vanadium precipitation.

As shown by Figures 16 and 17, we know that the precipitation product prepared under the above conditions in the laboratory is composed of ammonium hexavanadate hydrate, $\left(\mathrm{NH}_{4}\right)_{2} \mathrm{~V}_{6} \mathrm{O}_{16} \cdot 1.5 \mathrm{H}_{2} \mathrm{O}$, which forms in spheroid and ellipsoid with rough surface, leading to absorption of a small amount of manganese during the precipitation process. Vanadium pentoxide can be obtained after the crystal water and ammonia are evaporated from the ammonium hexavanadate hydrate with heating. In order to determine an appropriate heating temperature, some of the precipitation product was used to con- 
duct thermogravimetric analysis, which was carried out at a heating rate of $10{ }^{\circ} \mathrm{C} \cdot \mathrm{min}^{-1}$ over temperatures ranging from 28 to $650^{\circ} \mathrm{C}$, and air was introduced at a flow rate of $50 \mathrm{~mL} \cdot \mathrm{min}^{-1}$ during the heating process. $150 \mathrm{mg}$ precipitation product which had been dried at $90^{\circ} \mathrm{C}$ for $12 \mathrm{~h}$ was placed into an alumina crucible. The curves of TG-DTG (Thermal gravity-Differential thermal gravity) for this precipitation product are shown in Figure 18.

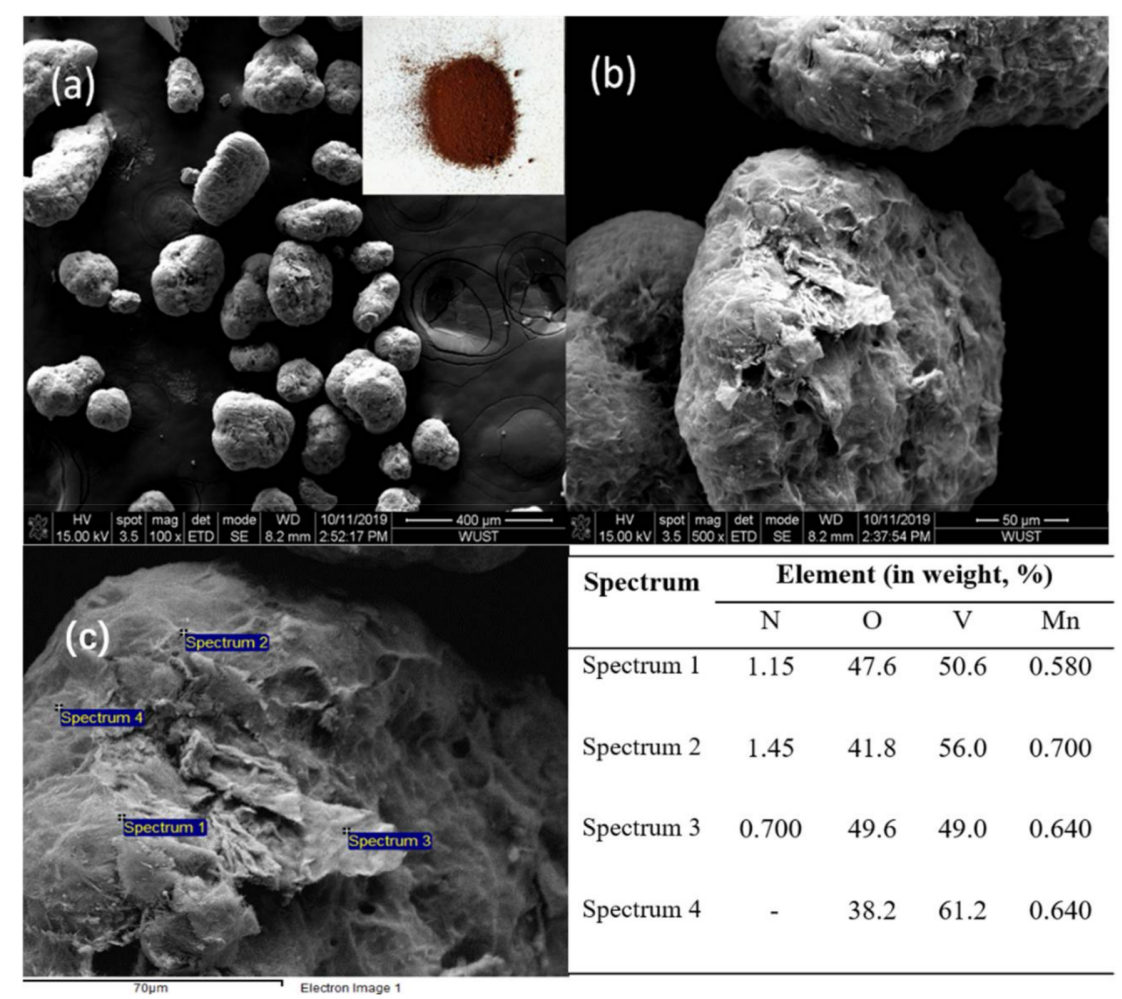

Figure 17. SEM-EDS analysis for vanadium precipitation, (a) magnification $\times 100$, (b) magnification $\times 500$, (c) magnification $\times 1000$.

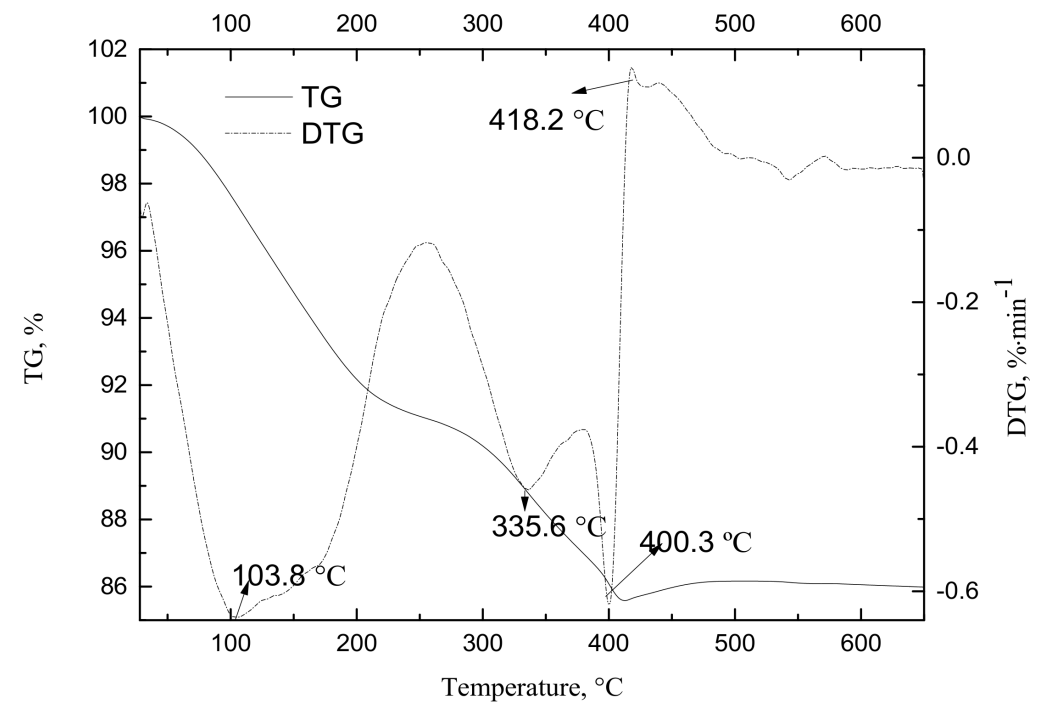

Figure 18. TG-DTG curves for ammonium polyvanadate heated from 28 to $650{ }^{\circ} \mathrm{C}$.

The TG curve during the heating process from room temperature to $650^{\circ} \mathrm{C}$, displays a mass loss of $14.42 \%$ appearing over temperatures ranging from 28 to $412.5^{\circ} \mathrm{C}$, and then a mass gain of $0.58 \%$ follows during heating from 412.52 to $501.5^{\circ} \mathrm{C}$. The mass loss 
occurring at temperatures lower than $412.5^{\circ} \mathrm{C}$ is attributed to reactions of dehydration and deamination, displayed as Equation (3):

$$
\begin{gathered}
\left(\mathrm{NH}_{4}\right)_{2} \mathrm{~V}_{6} \mathrm{O}_{16} \cdot \times 1.5 \mathrm{H}_{2} \mathrm{O}=3 \mathrm{~V}_{2} \mathrm{O}_{5}+2.5 \mathrm{H}_{2} \mathrm{O}+2 \mathrm{NH}_{3} \uparrow \\
3 \mathrm{~V}_{2} \mathrm{O}_{5}+2 \mathrm{NH}_{3}=3 \mathrm{~V}_{2} \mathrm{O}_{4}+3 \mathrm{H}_{2} \mathrm{O}+\mathrm{N}_{2} \uparrow
\end{gathered}
$$

As illustrated by DTG (Differential thermal gravity) curves, there are three extreme temperature points appearing in the weight loss process. The temperatures of 103.8, 335.6 and $400.3{ }^{\circ} \mathrm{C}$ represent the temperatures points at which reactions of dehydration, deamination and reduction of $\mathrm{V}_{2} \mathrm{O}_{5}$ (Equation (4)) take place at a maximum rate, respectively. When the temperature is over $412.5^{\circ} \mathrm{C}$, as ammonia gas decreases and oxygen partial pressure increases, the low valent vanadium oxide $\left(\mathrm{V}_{2} \mathrm{O}_{4}\right)$ is oxidized as $\mathrm{V}_{2} \mathrm{O}_{5}$ again. Additionally, in vanadium industry, ammonium polyvanadate is usually heated above the melting point temperature of vanadium pentoxide using a reverberatory furnace and then is pressed into a flake. The melting process is also beneficial for desulfuration from the product of vanadium pentoxide.

Based on the results of the thermogravimetric analysis, the precipitation product was heated at $550{ }^{\circ} \mathrm{C}$ for $2 \mathrm{~h}$ to fully remove water and ammonium, and consequently, saffron yellow vanadium pentoxide powder was produced. The chemical composition of the vanadium pentoxide product is presented in Table 7 and the XRD and SEM characterizations for the product are shown in Figures 19 and 20.

Table 7. Chemical composition of the vanadium pentoxide powder (wt. \%).

\begin{tabular}{cccccccccc}
\hline $\mathbf{V}_{\mathbf{2}} \mathbf{O}_{\mathbf{5}}$ & $\mathbf{M n}$ & $\mathbf{S}$ & $\mathbf{S i}$ & $\mathbf{F e}$ & $\mathbf{A l}$ & $\mathbf{P}$ & $\mathbf{C a}$ & $\mathbf{N a}_{2} \mathbf{O}$ & $\mathbf{K}_{\mathbf{2}} \mathbf{O}$ \\
\hline 98.6 & 0.850 & 0.0110 & 0.0310 & 0.0120 & 0.0110 & 0.0160 & 0.00700 & - & 0.0110 \\
\hline
\end{tabular}

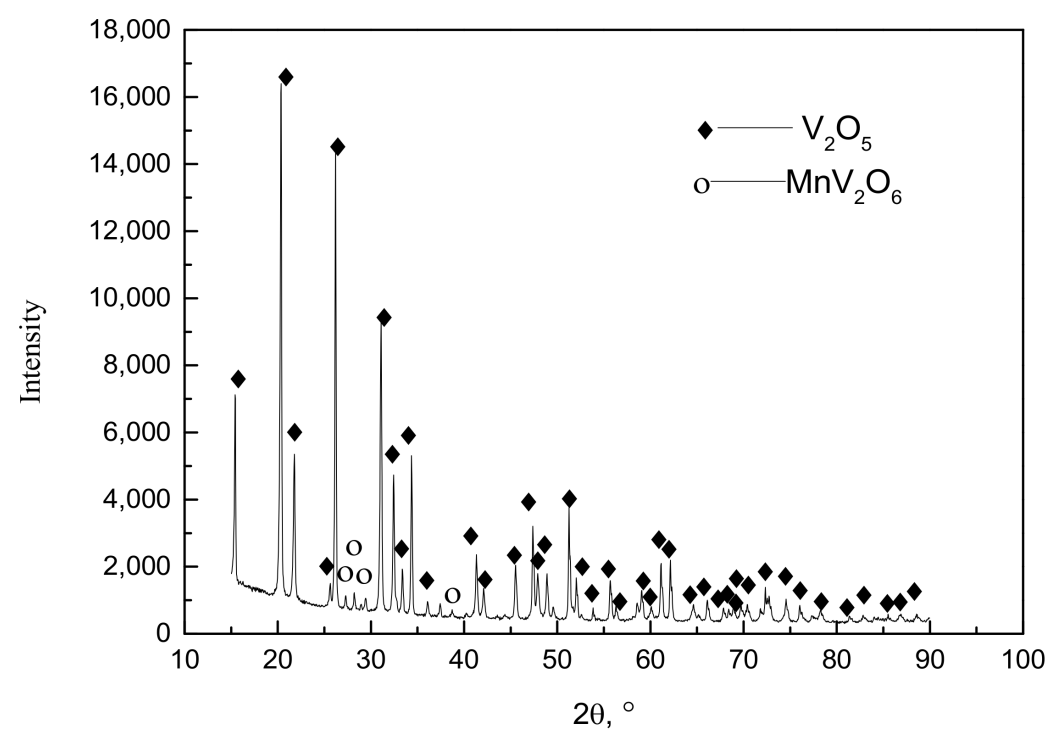

Figure 19. X-ray diffraction pattern of the vanadium pentoxide powder.

From Table 7 and Figures 19 and 20, it is known that the vanadium pentoxide powder is mainly composed of $\mathrm{V}_{2} \mathrm{O}_{5}$ and a little amount of manganese metavanadate $\left(\mathrm{MnV}_{2} \mathrm{O}_{6}\right)$ and exists in columnar crystals. The contents of $\mathrm{V}_{2} \mathrm{O}_{5}$ and other impurity elements contained in the product of vanadium pentoxide powder meet the Chinese standard of YB/T 5304-2017, suggesting that the purification method proposed in this study is feasible for treating the acidic vanadium-bearing solution. 


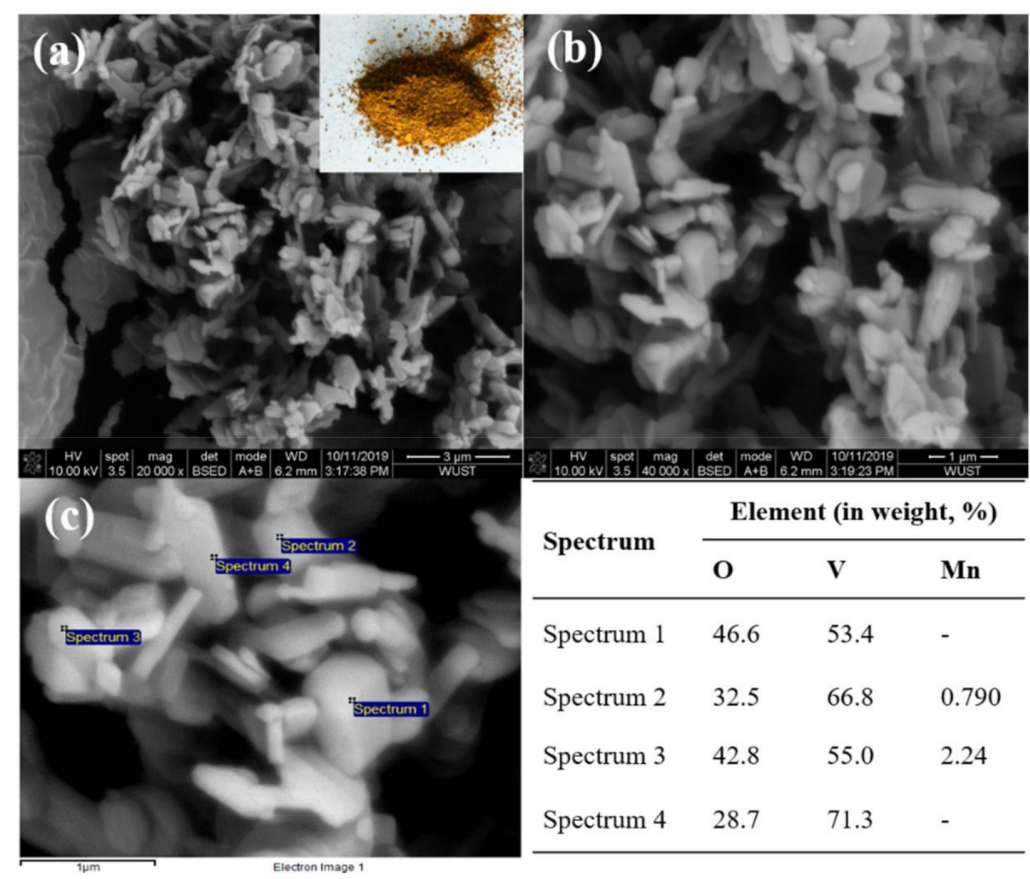

Figure 20. SEM-EDS of the vanadium pentoxide powder, (a) magnification $\times 20,000$, (b) magnification $\times 40,000$, (c) magnification $\times 80,000$.

\subsection{Evaluation of the Whole Purification Process}

In the whole purification process of the proposed chemical precipitation, no other ions are introduced into the acidic vanadium-bearing solution, hence no new impurity elements will appear in the final product of vanadium pentoxide. Especially, no alkali metal ions of $\mathrm{Na}^{+}$and $\mathrm{K}^{+}$are introduced, which is beneficial to realize the closed cycle of the leaching solution in the process of calcification roasting.

The chemical precipitation method used to purify the acidic vanadium-bearing solution with the remover of $\mathrm{MnNH}_{4} \mathrm{~F}_{3}$ prepared in this study combines the neutralization precipitation and fluoride precipitation into one operation step, and then can remove $\mathrm{Ca}, \mathrm{Mg}, \mathrm{Al}$ and partial Si simultaneously in an acidic $\mathrm{pH}$ range. The whole purification operation is simple, only involving precipitation and filtration.

After purification with the proposed chemical precipitation method, the removals of $\mathrm{Ca}, \mathrm{Mg}$ and $\mathrm{Si}$ are all over $95 \%$, and removal of $\mathrm{Si}$ is around $55 \%$; meanwhile, the loss of $\mathrm{V}$ is around $4 \%$, which is acceptable.

In the case of acidic vanadium-bearing solution used in this study, $0.0979 \mathrm{~mol} \mathrm{MnNH}_{4} \mathrm{~F}_{3}$ is added per liter of solution at the optimum adding amount. This means $0.0979 \mathrm{~mol}$ $\mathrm{MnSO}_{4} \cdot \mathrm{H}_{2} \mathrm{O}$ and $0.294 \mathrm{~mol} \mathrm{NH} \mathrm{N}_{4} \mathrm{~F}$ are consumed to treat $1 \mathrm{~L}$ solution. According to the market prices of $\mathrm{MnSO}_{4} \cdot \mathrm{H}_{2} \mathrm{O}$ (3000 RMB (Chinese Yuan) $\cdot \mathrm{t}^{-1}$, purity $\geq 97 \%$ ) and $\mathrm{NH}_{4} \mathrm{~F}$ $\left(7800 \mathrm{RMB}^{-1} \mathrm{t}^{-1}\right.$, purity $\left.\geq 98 \%\right)$, it costs $0.138 \mathrm{RMB}\left(0.0979 \times 169 / 0.97 \times 3 \times 10^{-3}+0.294 \times\right.$ $37 / 0.98 \times 7.8 \times 10^{-3}$ ) to purify $1 \mathrm{~L}$ vanadium-bearing solution. If calculated based on the weight of vanadium pentoxide, it costs 3611 RMB per ton.

Since the process of calcium roasting followed by dilute acid leaching is not commercial presently, and lots of studies on the purification of this kind of vanadium-bearing solution have been carried out only at laboratory scale, solvent extraction with organophosphorus acids, like D2EHPA (Di(2-ethylhexyl) phosphoric acid, P204), EHEHPA (2-Ethylhexyl phosphonic acid mono-2-ethylhexyl phosphoric ester, P507), Cyanex 272 (Di(2,4,4-trimethypentyl) phosphinic acid, TBP (Tributylphosphate) and so on, is commonly used to separate and concentrate vanadium from the acidic vanadium-bearing solution. Here, the cost of pretreatment of solution before solvent extraction, including $\mathrm{pH}$ adjustment, reduction of $\mathrm{Fe}^{3+}$ and $\mathrm{V}^{5+}$ and regeneration of solvent extractant is not considered, and only the cost of extraction and stripping is calculated when synergistic extraction of P204 and TBP is 
taken as an example. It is supposed that the organic phase is composed of $15 \% \mathrm{P} 204,5 \%$ TBP and $80 \%$ sulfonated kerosene, and the organic to aqueous volume ratio (O/A) is 1:1. The counter current stripping is conducted with $1.5 \mathrm{M} \mathrm{H}_{2} \mathrm{SO}_{4}$ at an O/A ratio of 5:1 for three stages [30]. The prices of P204 (purity $\geq 98 \%, \rho=0.960 \mathrm{~g} \mathrm{~mL}^{-1}$ ), TBP (purity $\geq 97 \%$, $\rho=0.977 \mathrm{~g} \mathrm{~mL}^{-1}$ ), sulfonated kerosene (purity $\geq 99 \%, \rho=0.780 \mathrm{~g} \mathrm{~mL}^{-1}$ ) and the concentrated sulfuric acid (purity $\geq 99 \%, \rho=1.84 \mathrm{~g} \mathrm{~mL}^{-1}$ ) are 18,000 RMB $\cdot \mathrm{t}^{-1}, 15,000 \mathrm{RMB} \mathrm{t}^{-1}$, $6100 \mathrm{RMB} \mathrm{t}^{-1}$ and $300 \mathrm{RMB} \mathrm{t}^{-1}$, respectively. Purification of $1 \mathrm{~L}$ vanadium-bearing solution consumes 150 mL P204, 50.0 mL TBP, 800 mL sulfonated kerosene and $50.0 \mathrm{~mL}$ concentrated sulfuric acid, and then the cost of purification of $1 \mathrm{~L}$ vanadium-bearing solution is calculated as around 7.16 RMB. Hence, in comparison with the solvent extraction, the method of chemical precipitation proposed in this study has an obvious advantage in cost and operation.

The precipitate obtained from the purification process is rich in $\mathrm{CaF}_{2}$ and $\mathrm{MgF}_{2}$, which is a fluoride source used as molten salt electrolyte additives or used as flux in pyrometallurgy, because no $\mathrm{Na}^{+}$or $\mathrm{K}^{+}$, which seriously corrode the furnace lining, is contained.

\section{Conclusions}

The main impurities contained in the acidic vanadium-bearing solution from calcified roasting process which influence the grade of the vanadium pentoxide product are $\mathrm{Ca}, \mathrm{Mg}$, $\mathrm{Al}$, Si and Mn. Using neutralization precipitation to remove Al and Si and using fluoride precipitation to remove $\mathrm{Ca}$ and $\mathrm{Mg}$ were well-combined into one operation step when the remover of $\mathrm{MnNH}_{4} \mathrm{~F}_{3}$ prepared in this study was used to purify the acidic vanadiumbearing solution. The main conclusions drawn from this study are listed as follows:

(1) The precipitant of $\mathrm{MnNH}_{4} \mathrm{~F}_{3}$ is superior to $\mathrm{NH}_{4} \mathrm{~F}$ in removing impurities from the acidic vanadium-bearing solution at $\mathrm{pH}$ lower than 4.50 when the removals of impurities and the loss of $\mathrm{V}$ are comprehensively considered.

(2) The removals of $\mathrm{Ca}, \mathrm{Mg}$ and $\mathrm{Al}$ were all over $95 \%$, while the loss of $\mathrm{V}$ during purification was lower than $5 \%$ when the precipitant of $\mathrm{MnNH}_{4} \mathrm{~F}_{3}$ was used to purify the acidic vanadium-bearing solution. Adding the flocculant of polyacrylamide is conductive to accelerating the sedimentation of the precipitant and reducing the loss of V. Meanwhile, the filter aid of diatomaceous can improve the filtration performance of the slurry.

(3) Reactions between the impurities of $\mathrm{Ca}^{2+}$ and $\mathrm{Mg}^{2+}$ in the acidic vanadium-bearing solution and the $\mathrm{F}^{-}$take place on the surface of particles of $\mathrm{MnNH}_{4} \mathrm{~F}_{3}$.

(4) The removals of $\mathrm{Mn}$ and the loss of $\mathrm{V}$ appeared in the same trend when ammonium persulfate was used to separate $\mathrm{Mn}$ from the solution which was purified with $\mathrm{MnNH}_{4} \mathrm{~F}_{3}$. The impurity of $\mathrm{Mn}$ can be effectively removed, but the loss of $\mathrm{V}$ is unsatisfactory, hence, the oxidation precipitation method with ammonium persulfate is not appropriate to treat the high concentration of $\mathrm{Mn}^{2+}$ in the acidic vanadiumbearing solution.

(5) After purification through adding $\mathrm{MnNH}_{4} \mathrm{~F}_{3}$ and adjusting the solution $\mathrm{pH}$, the vanadium pentoxide produced from the purified vanadium-containing solution with ammonium salt precipitation meets the Chinese standard of grade 98.

Author Contributions: Conceptualization, J.Z. and W.Z.; methodology, J.Z. and W.Z.; software, J.Z.; validation, J.Z., W.Z. and C.L.; formal analysis, J.Z., W.Z. and C.L.; investigation, J.Z.; resources, J.Z.; data curation, J.Z.; writing-original draft preparation, J.Z.; writing-review and editing, W.Z. and C.L.; visualization, J.Z. and C.L.; supervision, J.Z.; project administration, J.Z.; funding acquisition, J.Z., W.Z. and C.L. All authors have read and agreed to the published version of the manuscript.

Funding: This project was financially supported by the National Natural Science Foundation of China (No. 51804230, 51804228) and China Postdoctoral Science Foundation (No. 2020M672425).

Data Availability Statement: Not applicable. 
Acknowledgments: We gratefully acknowledge the Sichuan Weiyuan Iron \&Steel Co., Ltd. for providing samples of vanadium slag.

Conflicts of Interest: The authors declare no conflict of interest. The funders had no role in the design of the study; in the collection, analyses, or interpretation of data; in the writing of the manuscript, or in the decision to publish the results.

\section{References}

1. Moskalyk, R.R.; Alfantazi, A.M. Processing of vanadium: A review. Miner. Eng. 2003, 16, 793-805. [CrossRef]

2. Mahdavian, A.; Shafyei, A.; Keshavarz Alamdari, E.; Haghshenas, D.F. Recovery of Vanadium from Esfahan Steel Company Steel Slag; Optimizing of Roasting and Leaching Parameters. Int. J. Iron Steel Soc. Iran 2006, 3, 17-21.

3. Sun, Z.H. Analysis on new vanadium technologies and prospects of vanadium industry. Iron Steel Vanadium Titan. 2012, 33, 1-7.

4. Polyak, E.D. U.S. Geological Survey 2009 Minerals Yearbook-Vanadium; Geological Survey: Reston, VA, USA, 2011.

5. Kozlov, V.A.; Demidov, A.E. Chemical principles of a technology for making pure vanadium pentoxide. Metallurgist 2000, 44, 428-433. [CrossRef]

6. Li, Q.W.; Liu, F.Q.; Deng, X.B.; Hu, L. Study on Roasting of Pangang Converter Vanadium Slag with Soda in Laboratory. Iron Steel Vanadium Titan. 2012, 33, 8-11.

7. Li, X.S.; Xie, B.; Wang, G.E.; Li, X.J. Oxidation process of low-grade vanadium slag in presence of $\mathrm{Na}_{2} \mathrm{CO}_{3}$. Trans. Nonferrous Met. Soc. China 2011, 21, 1860-1867. [CrossRef]

8. Hao, J.Z.; Liu, A.Q. Utilization of wastes produced in the production process of vanadium. China Resour. Compr. Util. 2009, 27, 7-9.

9. $\quad$ Peng, Y.; Zhou, Y.P.; Bian, W.; Sun, Z.H.; Fan, Z.; Fu, Z.B. A Cleaner Process for Vanadium Pentoxide Production. China Patent No. 2,008,103,056,018, 22 April 2009.

10. Wang, M.; Xing, H.B.; Jia, Y.X.; Ren, Q.C. A zero-liquid-discharge scheme for vanadium extraction process by electrodialysis-based technology. J. Hazard. Mater. 2015, 300, 322-328. [CrossRef]

11. Deng, R.R.; Xiao, H.; Xie, Z.M.; Liu, Z.H.; Yu, Q.; Chen, G.; Tao, C.Y. A novel method for extracting vanadium by low temperature sodium roasting from converter vanadium slag. Chin. J. Chem. Eng. 2020, 28, 2208-2213. [CrossRef]

12. Zheng, S.L.; Du, H.; Zhang, Y.; Chen, D.H.; Bai, R.G. Efficient and cleaner technology of vanadium extraction from vanadium slag by sub-molten salt method. Gang Tie Fan Tai 2012, 33, 15-19.

13. Liu, B.; Du, H.; Wang, S.N.; Zhang, Y.; Zheng, S.L.; Li, L.J.; Chen, D.H. A novel method to extract vanadium and chromium from vanadium slag using molten $\mathrm{NaOH}-\mathrm{NaNO}_{3}$ binary system. AIChE J. 2013, 59, 541-552. [CrossRef]

14. Liu, H. Bin; Du, H.; Wang, D.W.; Wang, S.N.; Zheng, S.L.; Zhang, Y. Kinetics analysis of decomposition of vanadium slag by KOH sub-molten salt method. Trans. Nonferrous Met. Soc. China 2013, 23, 1489-1500. [CrossRef]

15. Liu, F.; Ning, P.G.; Cao, H.B.; Zhang, Y. Measurement and modeling for vanadium extraction from the $\left(\mathrm{NaVO}_{3}+\mathrm{H}_{2} \mathrm{SO}_{4}+\mathrm{H}_{2} \mathrm{O}\right)$ system by primary amine N1923. J. Chem. Thermodyn. 2015, 80, 13-21. [CrossRef]

16. Wang, Z.H.; Zheng, S.L.; Wang, S.N.; Qin, Y.L.; Du, H.; Zhang, Y. Electrochemical decomposition of vanadium slag in concentrated $\mathrm{NaOH}$ solution. Hydrometallurgy 2015, 151, 51-55. [CrossRef]

17. Xiang, J.Y.; Huang, Q.Y.; Lv, X.W.; Bai, C.G. Extraction of vanadium from converter slag by two-step sulfuric acid leaching process. J. Clean. Prod. 2018, 170, 1089-1101. [CrossRef]

18. Zhang, G.Q.; Zhang, T.A.; Lü, G.Z.; Zhang, Y.; Liu, Y.; Xie, G. Extraction of vanadium from LD converter slag by pressure leaching process with titanium white waste acid. Rare Met. Mater. Eng. 2015, 44, 1894-1898.

19. Liu, Z.H.; Li, Y.; Chen, M.L.; Nueraihemaiti, A.; Du, J.; Fan, X.; Tao, C.Y. Enhanced leaching of vanadium slag in acidic solution by electro-oxidation. Hydrometallurgy 2016, 159, 1-5. [CrossRef]

20. Mirazimi, S.M.J.; Rashchi, F.; Saba, M. A new approach for direct leaching of vanadium from LD converter slag. Chem. Eng. Res. Des. 2015, 94, 131-140. [CrossRef]

21. Li, H.Y.; Wang, C.J.; Yuan, Y.H.; Guo, Y.; Diao, J. Magnesiation roasting-acid leaching: A zero-discharge method for vanadium extraction from vanadium slag. J. Clean. Prod. 2020, 260, 121091. [CrossRef]

22. Xiang, J.Y.; Wang, X.; Pei, G.S.; Huang, Q.Y.; Lv, X.W. Recovery of vanadium from vanadium slag by composite roasting with $\mathrm{CaO} / \mathrm{MgO}$ and leaching. Trans. Nonferrous Met. Soc. China 2020, 30, 3114-3123. [CrossRef]

23. Wen, J.; Jiang, T.; Wang, J.; Lu, L.; Sun, H. Cleaner extraction of vanadium from vanadium-chromium slag based on MnO2 roasting and manganese recycle. J. Clean. Prod. 2020, 261, 121205. [CrossRef]

24. Zhang, G.Q.; Luo, D.M.; Deng, C.H.; Lv, L.; Liang, B.; Li, C. Simultaneous extraction of vanadium and titanium from vanadium slag using ammonium sulfate roasting-leaching process. J. Alloys Compd. 2018, 742, 504-511. [CrossRef]

25. Zhang, J.H.; Zhang, W.; Xue, Z.L. Oxidation kinetics of vanadium slag roasting in the presence of calcium oxide. Miner. Process. Extr. Metall. Rev. 2017, 38, 265-273. [CrossRef]

26. Wang, M.Y.; Zhang, G.Q.; Wang, X.W.; Zhang, J.L. Solvent extraction of vanadium from sulfuric acid solution. Rare Met. 2009, 28, 209-211. [CrossRef]

27. Painuly, A.S. Separation and recovery of vanadium from spent vanadium pentaoxide catalyst by Cyanex 272. Environ. Syst. Res. 2015, 4, 1-7. [CrossRef] 
28. Zhang, Y.; Zhang, T.A.; Lv, G.Z.; Zhang, G.Q.; Liu, Y.; Zhang, W. Synergistic extraction of vanadium(IV) in sulfuric acid media using a mixture of D2EHPA and EHEHPA. Hydrometallurgy 2016, 166, 87-93. [CrossRef]

29. Guo, Y.; Li, H.Y.; Shen, S.; Wang, C.J.; Diao, J.; Xie, B. Recovery of vanadium from vanadium slag with high phosphorus content via recyclable microemulsion extraction. Hydrometallurgy 2020, 198, 105509. [CrossRef]

30. Zhang, J.H.; Zhang, W.; Zhang, L.; Gu, S.Q. A critical review of technology for selective recovery of vanadium from leaching solution in $\mathrm{V}_{2} \mathrm{O}_{5}$ production. Solvent Extr. Ion Exch. 2014, 32, 221-248. [CrossRef]

31. Zhang, J.H.; Zhang, W.; Zhang, L.; Gu, S.Q. Effect of acid leaching on the vanadium leaching rate in process of vanadium extraction using calcium roasting. Dongbei Daxue Xuebao. 2014, 35, 1574-1578.

32. Zhang, J.H. A Cleaner Process for Preparation of $V_{2} \mathrm{O}_{5}$ from Converter Vanadium Slag; Northeastern University: Liaoning, China, 2014.

33. Vanadium Pentoxide: YB/T 5304-2017; Ministry of Industry and Information Technology: Beijing, China, 2017 ; pp. 1-5.

34. Yang, H.X.; Ling, Z.; Yan, X.R. Inorganic Chemistry, 3rd ed.; Higher Education Press: Beijing, China, 2002.

35. Silva, A.M.; Cunha, E.C.; Silva, F.D.R.; Leão, V.A. Treatment of high-manganese mine water with limestone and sodium carbonate. J. Clean. Prod. 2012, 29-30, 11-19. [CrossRef]

36. Liu, H.G.; Zhu, G.C. Removal of $\mathrm{Ca}(\mathrm{II}), \mathrm{Mg}$ (II) from leaching solution of low-grade manganese ore by precipitation with fluoride. Mining Metall. 2007, 6, 25-28.

37. Li, J.Q.; Wang, J.W.; Mao, X.H.; Zhao, P.Y. Research on magnesium removing from $\mathrm{MnCl}_{2}$ solution with MnF 2 . Nonferrous Met. Extractive Metall. 2012, 21-23.

38. Gong, Z.Q.; Zhao, H.; Huang, J.; Chen, W. Study on technology of removing $\mathrm{Ca}^{2+}, \mathrm{Mg}^{2+}$ from crude nickle sulfate. Inorg. Chem. Ind. 2000, 32, 16-17.

39. Li, B.; Wei, Y.; Wang, H.; Yang, Y.D.; Yin, Y.G. Preparation of $\mathrm{ZnSO}_{4} \cdot 7 \mathrm{H}_{2} \mathrm{O}$ and separation of zinc from blast furnace sludge by leaching-purification-crystallization method. ISIJ Int. 2019, 59, 201-207. [CrossRef]

40. Yin, J.R.; Zhu, D.H.; Fuyi, B.; Yun, L.; Wang, L.P. Removal of $\mathrm{Mn}^{2+}$ from $\mathrm{CoCl}_{2}$ solution by precipitation with $\mathrm{KMnO}_{4}$. Nonferrous Met. 1996, 48, 58-60.

41. Bolton, G.L.; Sefton, V.B.; Zubryckyj, N. Removal of Manganese and Chloride Ions from Aqueous Acidic Zinc Sulphate Solutions. U.S. Patent No. 4,379,037, 5 April 1983.

42. Sun, Y.Y.; Huang, X.; Jing, Z.Q.; Cao, S.W. Adsorption of manganese ions by fly ash filter material. Energy Environ. Prot. 2011, 25, 4-9.

43. Rajic, N.; Stojakovic, D.; Jevtic, S.; Zabukovec Logar, N.; Kovac, J.; Kaucic, V. Removal of aqueous manganese using the natural zeolitic tuff from the Vranjska Banja deposit in Serbia. J. Hazard. Mater. 2009, 172, 1450-1457. [CrossRef] [PubMed]

44. Fan, X.X.; Peng, J.H.; Zhang, L.B.; Zhang, S.M.; Guo, S.H. Process research of oxidizing removing manganese(II)ion in zinc sulfate solution by ammonium peroxysulphate. Non-ferous Min. Metall. 2002, 18, 38-41.

45. Zhang, W.S.; Cheng, C.Y.; Pranolo, Y. Investigation of methods for removal and recovery of manganese in hydrometallurgical processes. Hydrometallurgy 2010, 101, 58-63. [CrossRef]

46. Zhang, W.; Cheng, C.Y. Manganese metallurgy review. Part II: Manganese separation and recovery from solution. Hydrometallurgy 2007, 89, 160-177. [CrossRef] 